\title{
La incapacidad temporal laboral en los tiempos del COVID-19, aspectos preventivos y consecuencias
}

\section{Temporary incapacity for work (sick leave) in the times of COVID-19, preventive aspects and consequences}

José Manuel Vicente-Pardo ${ }^{1}$

Araceli López-Guillén-García ${ }^{2}$

${ }^{1}$ Universidad Católica de Murcia UCAM. Cátedra de Medicina Evaluadora y Pericial. Jefe Unidad Médica Equipo Valoración Incapacidades. Instituto Nacional de la Seguridad Social. Gipuzkoa. España.

${ }^{2}$ Universidad Católica de Murcia UCAM. Cátedra de Medicina Evaluadora y Pericial. Unidad Médica Equipo Valoración Incapacidades. Instituto Nacional de la Seguridad Social. Murcia. España.

\section{Correspondencia}

José Manuel Vicente Pardo josemanuvicente@gmail.com

Recibido: 30.01 .2021

Aceptado: 12.03.2021

Publicado: 31.03.2021

\section{Contribuciones de autoría}

Las autoras y los autores de este trabajo han contribuido por igual.

\section{Financiación}

Sin financiación.

\section{Conflicto de intereses}

No existe conflicto de intereses.

\section{How to cite this paper}

Vicente-Pardo JM, López-Guillén-García A. La incapacidad temporal laboral en los tiempos del COVID-19, aspectos preventivos y consecuencias. Med Segur Trab (Internet). 2021;67(262):37-72. doi: 10.4321/s0465-546x2021000100004

(c) BY-NC-SA 4.0 


\title{
Resumen
}

Introducción: La incapacidad temporal por COVID-19 fue regulada de forma expresa, mediante diversas normas e instrucciones, cubriendo tanto el aislamiento por contacto, por infección o para trabajadores sensibles. Supuso la integración de la protección preventiva laboral amparada su protección en una la prestación económica dotada de mayor cuantía. Analizando las consecuencias de la pandemia en la primera ola, confinamiento, desescalada y vuelta a la normalidad, meses de marzo a octubre, el impacto «colapsante» del COVID-19 en el sistema sanitario supuso la paralización y el aumento de listas de espera para pruebas, operaciones y consultas no urgentes del resto de patologías, y consecuentemente un elevado incremento de la duración media de las bajas laborales por todos los procesos, en el confinamiento y la desescalada en un $84,48 \%$ y en un $25,27 \%$ las bajas prolongadas que alcanzaron más de 365 días. En consecuencia, el COVID-19 como efecto colateral supuso una mala evolución del resto de procesos, prolongando la duración de las incapacidades temporales, lo que supone un empeoramiento de la salud laboral, un riesgo mayor de no retorno al trabajo que sucede en las bajas largas, mayor riesgo de desempleo, un mayor gasto en prestaciones y un deterioro económico para empresas y autónomos. La incapacidad temporal por COVID-19 suponía al final de octubre 2020 el 38,73\% de todas las bajas.

Material y Método: Se analizaron los datos suministrados por la Seguridad Social, por el INSS y el Ministerio de Sanidad, se elaboraron para poder extraer datos para poder valorar el impacto del COVID-19 en la incapacidad temporal laboral. Se revisaron hasta octubre de 2019 las siguientes bases de datos bibliográficas: SciELO, PUBMED. Así mismo otras referencias que incluimos en bibliografía.

Objetivo: Recoger de forma sintética la norma aplicable, las situaciones protegidas, y cuantificar el impacto en las bajas, incapacidad laboral, de la pandemia.

Conclusiones: La pandemia obligó a priorizar recursos en torno al COVID-19, colapsando la atención del resto de patologías, salvo urgencias o tratamientos vitales. Esto supuso el aumento de las listas de espera para consultas, pruebas o intervenciones quirúrgicas no urgentes, así como la anulación o postergación de consultas o tratamientos y por ello un incremento en la duración mayor de las bajas laborales y además el empeoramiento de la salud laboral, en consecuencia, al no poder disponer de tratamiento en tiempo y forma. En el confinamiento y la desescalada la duración media de las bajas se incrementó en un 84,48\%; por procesos el incremento fue del 503,58\% en las enfermedades respiratorias, del $215,88 \%$, en las enfermedades infecciosas, del $60,73 \%$ en las enfermedades endocrinas, del 45;42\% de las enfermedades de la sangre, del 45,09\% de las enfermedades digestivas, del 35,63\% en los trastornos osteomioarticulares, del 34,12\% en las neoplasias, del 33,37\% en las enfermedades circulatorias, del $31,94 \%$ de los «procedimientos», y del $29,56 \%$ de los trastornos mentales. Las bajas prolongadas (PIT) que alcanzaron los 365 días se incrementaron en un 25,27\%, respecto del mes de octubre del año anterior. Las bajas prolongadas por enfermedades endocrinas y de la nutrición se incrementaron en un 28,50, por trastornos mentales en un $28,20 \%$, por trastornos osteomusculares en un 26,70 , por neoplasias en un $26,49 \%$, por enfermedades respiratorias en un $24,27 \%$, por enfermedades del sistema nervioso en un $22,79 \%$, por enfermedades cardiovasculares en un $20,48 \%$, y por enfermedades digestivas en un $19,24 \%$. Como consecuencia del COVID-19, se expuso a un riesgo añadido y nuevo a la población trabajadora; sanitarios y socio sanitarios sufrieron la enfermedad como consecuencia directa de su trabajo por enfermedad de indudable carácter profesional. Los efectos del COVID-19 en el retraso de pruebas, cirugías o tratamientos en procesos «No COVID-19» y las dificultades de contacto asistencial empeoraron la salud laboral, prolongando las situaciones de incapacidad y elevando el riesgo que encierran las incapacidades prolongadas de no retorno laboral por la esperada mala evolución de cualquier proceso cuando no puede ser tratado y atendido de forma temprana.

Palabras clave: COVID-19; Incapacidad Temporal; absentismo por enfermedad; salud laboral; prevención.

\begin{abstract}
Introduction: Temporary disability due to COVID-19 was expressly regulated, through various rules and instructions, covering both isolation by contact, by infection or for sensitive workers. It involved the integration of preventive labor protection covered by its protection in a financial benefit with the highest amount. Analyzing the consequences of the pandemic in the first wave, confinement, de-escalation and return to normality, months from March to October, the "collapsing» impact of COVID-19 on the health system led to the paralysis and increase of waiting lists for tests, operations and non-urgent consultations of the rest of pathologies, and consequently a high increase in the average duration of sick leave for all processes, in confinement and de-escalation in $84.48 \%$ and in $25.27 \%$ the prolonged casualties that reached more than 365 days. Consequently, COVID-19 as a collateral effect led to a poor evolution of the rest of the processes, prolonging the duration of temporary disabilities, which implies a worsening of occupational health, a greater risk of not returning to work that occurs during sick leave long, higher risk of unemployment, higher spending on benefits and economic decline for companies and the self-employed. Temporary disability due to COVID-19 accounted for $38.73 \%$ of all casualties at the end of October 2020.
\end{abstract}


Conclusions: The pandemic forced to prioritize resources around COVID-19, collapsing the care of the rest of pathologies, except for emergencies or vital treatments. This meant an increase in waiting lists for non-urgent consultations, tests or surgical interventions, as well as the cancellation or postponement of consultations or treatments and therefore an increase in the longer duration of sick leave and also the worsening of occupational health, consequently, by not being able to have treatment in a timely manner. In confinement and de-escalation, the average duration of casualties increased by $84.48 \%$; by processes, the increase was $503.58 \%$ in respiratory diseases, $215.88 \%$, in infectious diseases, $60.73 \%$ in endocrine diseases, $45 ; 42 \%$ of blood diseases, $4509 \%$ for digestive diseases, $35.63 \%$ for osteomyoarticular disorders, 34.12\% for neoplasms, 33.37\% for circulatory diseases, 31.94\% for «procedures», and $29.56 \%$ of mental disorders. Long-term sick leave (PIT) that reached 365 days increased by $25.27 \%$, compared to the month of October of the previous year. Prolonged sick leave due to endocrine and nutritional diseases increased by 28.50 , from mental disorders by $28.20 \%$, from musculoskeletal disorders by 26.70 , from neoplasms by $26.49 \%$, from respiratory diseases in $24.27 \%$, for diseases of the nervous system in $22.79 \%$, for cardiovascular diseases in $20.48 \%$, and for digestive diseases in $19.24 \%$. As a consequence of COVID-19, the working population was exposed to an added and new risk; health and social health workers suffered the disease as a direct consequence of their work due to illness of an undoubted professional nature. The effects of COVID-19 on the delay of tests, surgeries or treatments in «No COVID-19» processes and the difficulties of contact with care worsened occupational health, prolonging disability situations and increasing the risk of prolonged non-COVID-19 disabilities, return to work due to the expected poor evolution of any process when it cannot be treated and attended to early.

Keywords: COVID-19; occupational disability; sick leave; sickness absence; occupational health; prevention.

\author{
Abreviaturas \\ AT: accidente de trabajo \\ EC: Enfermedad Común, no profesional \\ EVI: Equipo de Valoración de Incapacidades \\ INSS: Instituto Nacional de la Seguridad Social \\ IT: incapacidad temporal o baja \\ IP: Incapacidad Permanente \\ LGSS: Ley General de la Seguridad Social \\ PIT: procesos que alcanzan los 365 días de baja Prórroga Incapacidad Temporal, serán aludidos como «baja pro- \\ longada» \\ SPRL: Servicio de Prevención de Riesgos Laborales \\ TES: Trabajadores Especialmente Sensibles
}




\section{Introducción}

La consideración de la IT por COVID-19 ha supuesto una serie de cambios y adaptaciones normativas para su mayor protección económica y para dotarla de un carácter marcadamente preventivo ante la pandemia.

La actual pandemia del coronavirus, está suponiendo una extraordinaria situación crítica del sistema sanitario, de forma recurrente, además de una situación de crisis económica y social sostenida. Nuestro sistema de seguridad social como sistema de protección social ha dotado a la Incapacidad Temporal de unas consideraciones especiales «extraordinarias» que son una mayor dotación económica de esta prestación, asimilándola en su importe al del accidente de trabajo, y en su consideración preventiva ampliada, acogiendo como situación de IT el aislamiento por contacto, el confinamiento obligado e incluso las situaciones de trabajador sensible o vulnerable, o las que así fueran consideradas desde el servicio de prevención. Siguen firmes los conceptos de enfermedad profesional y accidente de trabajo, las situaciones que protegen, a quiénes, y su sistema especial de protección económica, preventiva e incluso de recargo de prestaciones por parte de la empresa cuando se dieran supuestos de contingencia laboral en los que la enfermedad se hubiera contraído por falta de medidas de seguridad e higiene en el trabajo.

A continuación, reflejaremos, instrucciones, normas, guías y consideraciones que se han ido desarrollando en torno a la incapacidad temporal por coronavirus; lo novedoso de las mismas respecto del concepto básico de la IT.

Análisis de la incapacidad temporal en la pandemia entre los meses de marzo a octubre incluido.

Y las conclusiones sobre el COVID-19 y la incapacidad temporal.

\section{La IT por COVID-19}

\subsection{Aspectos normativos de la Incapacidad Temporal por COVID-19 y situaciones protegi- das, codificación}

\subsubsection{Normas e instrucciones}

De forma básica recogemos las principales normas sobre IT y COVID-19:

Real Decreto Ley $\mathbf{6}$ de 2020, de $\mathbf{1 0}$ de marzo ${ }^{(1)}$ por el que se adoptan determinadas medidas urgentes en el ámbito económico y para la protección de la salud pública. Artículo quinto:

Al objeto de proteger la salud pública, se considerarán, con carácter excepcional, situación asimilada a accidente de trabajo, exclusivamente para la prestación económica de incapacidad temporal del sistema de Seguridad Social, aquellos periodos de aislamiento o contagio de las personas trabajadoras provocado por el virus COVID-19. La fecha del hecho causante será la fecha en la que se acuerde el aislamiento o enfermedad del trabajador, sin perjuicio de que el parte de baja se expida con posterioridad a esa fecha.

Criterio 4/2020 de la Seguridad Social DGOSS (Dirección General de Ordenación de la Seguridad Social) de 12 de marzo de $\mathbf{2 0 2 0 ^ { ( 2 ) }}$ sobre la aplicación del artículo quinto del Real Decreto Ley 6/2020, establece la retroactividad de la baja, la situación asimilada a accidente de trabajo exclusivamente para la prestación económica de incapacidad temporal, sin que, por tanto, se haga extensible dicha consideración a la prestación de asistencia sanitaria que derivará de contingencia común, salvo cuando se pruebe que la enfermedad se ha contraído con causa exclusiva en la realización del trabajo en cuyo caso será calificada como accidente de trabajo.

Disposición adicional vigésimo primera del Real Decreto-ley 11/2020, de 31 de marzo ${ }^{(3)}$, por el que se adoptan medidas urgentes complementarias en el ámbito social y económico para hacer frente al COVID-19, considera IT estas situaciones de obligado confinamiento. Con carácter excepcional, y con efectos desde el inicio de la situación de confinamiento, y mediante el correspondiente parte de baja, 
se extenderá esta protección a aquellos trabajadores obligados a desplazarse de localidad y tengan obligación de prestar los servicios esenciales a los que se refiere el Real Decreto-ley 10/2020, siempre que se haya acordado el confinamiento de la población donde tenga su domicilio y le haya sido denegada de forma expresa la posibilidad de desplazarse por la autoridad competente, no pueda realizar su trabajo de forma telemática por causas no imputables a la empresa para la que prestas sus servicios o al propio trabajador y no tenga derecho a percibir ninguna otra prestación pública. La acreditación del acuerdo de confinamiento de la población donde tiene el domicilio y la denegación de la posibilidad de desplazamiento se realizará mediante certificación expedida por el ayuntamiento del domicilio ante el correspondiente órgano del servicio público de salud. De igual forma, la imposibilidad de realización del trabajo de forma telemática se acreditará mediante una certificación de la empresa o una declaración responsable en el caso de los trabajadores por cuenta propia ante el mismo órgano del servicio público de salud.

Procedimiento de actuación para los servicios de prevención de riesgos laborales frente a la exposición al SARS-CoV-2 8 de abril de 2020. Colaboración en la gestión de la Incapacidad Temporal(4). Recogiendo la actividad colaboradora esencial sobre evaluación de riesgos, escenarios de riesgo en el trabajo, manejo del trabajador sensible, estudio de los casos, elaboración de informes, y tabulación de niveles de riesgo tanto de trabajadores sanitarios sociosanitarios y no sanitarios, así como colaboración mediante estos informes en la gestión de la Incapacidad Temporal. Los servicios de prevención están llamados a cooperar con las autoridades sanitarias en la detección precoz de todos los casos compatibles con COVID-19 y sus contactos, para controlar la transmisión. Corresponde a las empresas evaluar el riesgo de exposición en que se pueden encontrar las personas trabajadoras en cada una de las tareas diferenciadas que realizan y seguir las recomendaciones que sobre el particular emita el servicio de prevención, siguiendo las pautas y recomendaciones formuladas por las autoridades sanitarias. El servicio sanitario del servicio de prevención de riesgos laborales elaborará el informe para que quede acreditada la indicación de incapacidad temporal (IT), con el fin de facilitar a los servicios de atención primaria su tramitación, en:

- Los casos sospechosos o confirmados y los contactos estrechos de casos confirmados ocurridos en la empresa. Así como los casos confirmados para los que le sea requerido por la autoridad sanitaria.

- Las personas trabajadoras con especial sensibilidad en relación a la infección de coronavirus SARSCoV-2, sin posibilidad de adaptación del puesto de trabajo, protección adecuada que evite el contagio o reubicación en otro puesto exento de riesgo de exposición al SARS-CoV-2. En este caso, cuando se produzcan cambios en la evidencia científica disponible, en las condiciones de trabajo o en las medidas preventivas que hagan innecesaria la IT, el servicio de prevención debe reevaluar con los nuevos criterios o datos, los informes de indicación de IT emitidos que puedan verse afectados y facilitar su resultado, por la misma vía, a los servicios de atención primaria

Actualización a $\mathbf{1 5}$ de abril de $\mathbf{2 0 2 0}$ de las instrucciones aclaratorias relativas al nuevo procedimiento de remisión de partes de los servicios públicos de salud (SPS) por coronavirus ${ }^{(5)}$. Serán los médicos de los SPS los que emitan los partes de baja y alta en todos los casos de afectación por coronavirus (conforme a los códigos de la CIE9MC y a la CIE10ES consensuados), tanto en las situaciones de aislamiento como de enfermedad y a todos los trabajadores que por su situación clínica o indicación de aislamiento lo necesiten, tanto para el personal sanitario como para el resto de trabajadores. La contingencia a cumplimentar por parte de dichos facultativos de los SPS en los partes de baja/alta será siempre Enfermedad Común. No deben emitirse partes de baja por cualquier otra contingencia ya que en el INSS se realizará un procedimiento interno que permita diferenciar todas las bajas que lleguen por los diagnósticos que figuran en el apartado siguiente y convertirlas en AT.

Procede emitir parte de baja en casos de aislamiento:

No procede su emisión en los casos de personas trabajadoras sin causa actual de IT por sus patologías previas, que sean derivadas por las empresas o acudan ellas mismas a solicitar IT por temor al contagio de COVID19, salvo que se trate de personas trabajadoras especialmente sensibles (TES) al riesgo de SARSCOV-2. 
Sí procede su emisión (previo informe del servicio de prevención de riesgos laborales correspondiente) en aquellos casos de personas trabajadoras que presentan condiciones de salud que las hacen más vulnerables a COVID-19, y en los que, a pesar de las medidas de prevención, adaptación y protección establecidas, las condiciones de trabajo no les permitan efectuar su trabajo sin elevar el riesgo para sí mismas.

Se consideran personas vulnerables aquellas que presentan patologías cardiovasculares, hipertensión arterial, diabetes, enfermedad pulmonar crónica, inmunodeficiencias, procesos oncológicos en tratamiento activo, debiendo valorarse si esas patologías están controladas o descompensadas o con 2 o más comorbilidades. Todo ello debe conjugarse con los niveles de riesgo de las tareas a realizar (hasta 4 niveles) recogidos en el procedimiento elaborado por el Ministerio de Sanidad. Los servicios de prevención de riesgos laborales de las empresas serán los encargados de establecer la calificación como trabajadores especialmente sensibles, la naturaleza de la especial sensibilidad, las medidas de prevención, adaptación y protección posibles, teniendo en cuenta la existencia o no de condiciones que permitan a estas personas efectuar su trabajo sin elevar el riesgo para sí mismo.

Real Decreto-ley 19/2020, de 26 de mayo ${ }^{(6)}$, las enfermedades padecidas por el personal que presta servicio en centros sanitarios o socio-sanitarios, inscritos en los registros correspondientes, como consecuencia del contagio del virus SARS-CoV-2 durante el estado de alarma, tendrán consideración de contingencia profesional derivada de accidente de trabajo, cuando así se acredite por los servicios de Prevención de Riesgos Laborales y Salud Laboral. Esta previsión se aplicará a los contagios del virus SARS-CoV-2 producidos hasta el mes posterior a la finalización del estado de alarma, acreditando este extremo mediante el correspondiente parte de accidente de trabajo que deberá haberse expedido dentro del mismo periodo de referencia. Esto implica que desde el día 28 de mayo la emisión de los partes de baja y alta se realizará por la Mutua colaboradora con la Seguridad Social que corresponda. Esta consideración de contingencia laboral como accidente de trabajo se extiende y prorroga hasta que las autoridades sanitarias decreten el levantamiento de todas las medidas de prevención adoptadas para hacer frente a esta crisis sanitaria según Real Decreto-ley 27/2020, de 4 de agosto disposición adicional $8^{a}$.

\section{Actualización a $\mathbf{1 7}$ de junio de $\mathbf{2 0 2 0}$ de las instrucciones aclaratorias relativas a los procesos de Incapacidad Temporal emitidos a los Trabajadores Especialmente Sensibles por especial vulnera- bilidad frente al Coronavirus SARS- CoV-2 ${ }^{(7)}$.}

El INSS considera necesario revisar, con vistas a la emisión del correspondiente parte de alta, dos situaciones de incapacidad temporal diferenciadas:

- Procesos de IT emitidos a TES con el código específico (para codificación en CIE10 ES, el código Z29.8 y para codificación en CIE9MC, el código V07.8). Estos procesos, en general tienen una fecha de baja desde el 10/04/2020 en adelante.

- Procesos de IT emitidos para situaciones de aislamiento (para CIE-10 ES, el código Z20.828 y para CIE9, el código V01.79).

Estos procesos pueden tener una fecha de baja desde el 15/02/2020 en adelante. Estas bajas médicas emitidas inicialmente por aislamiento, en caso de que no hubieran derivado en enfermedad COVID19, no deberían haber tenido una duración superior a 14 días, salvo que, además, se trataran de TES y por ello se han mantenido de baja laboral. La fecha de alta será la que cumplimente el facultativo del SPS al emitir el correspondiente parte de alta. Para proceder a esta revisión, se considera que, al tratarse de procesos de IT que generalmente se han iniciado o se han mantenido por el facultativo de atención primaria, en base al correspondiente informe del Servicio de Prevención de Riesgos Laborales, es recomendable que de manera inmediata dichos SPRL utilicen el Anexo 3 (Especial sensibilidad. No hay necesidad de IT) del «Procedimiento de actuación para los servicios de prevención de riesgos laborales frente a la exposición al SARS-CoV-2», habida cuenta de que, como se ha indicado previamente, el escenario es de baja/muy baja transmisión, similar al riesgo comunitario desde el 21/06/2020. 
Si el SPRL considera de manera fehaciente la necesidad (por las especiales características del caso concreto) de mantener el proceso de incapacidad temporal, así se lo hará saber al facultativo del Servicio Público de Salud (SPS). Es recomendable que los informes de los SPRL le lleguen (previa comunicación al interesado) al facultativo responsable de la emisión del parte de baja y de alta lo antes posible, bien mediante su entrega por el propio asegurado, bien a través de los Servicios de Inspección Médica de los respectivos SPS o bien desde el propio SPRL al facultativo antes referido. Para estas comunicaciones se utilizarán preferentemente medios electrónicos. Los informes de los SPRL deben recoger la valoración individualizada de cada asegurado, pero eso sí, en el nuevo escenario de fin del estado de alarma y de las medidas que esa situación provocó en este aspecto, ya que, se insiste, el escenario de transmisión del coronavirus es de riesgo similar al riesgo comunitario (en estos momentos, bajo/muy bajo). En aquellos casos en que no se haya recibido en el SPS el informe del SPRL en uno u otro sentido, o se trate de asegurados que no dispongan de SPRL y que hubieran presentado una declaración jurada para acceder a la prestación de IT, la inspección médica del correspondiente SPS podrá hacer un seguimiento estrecho de los mismos y, previas las averiguaciones y comprobaciones pertinentes, podrá emitir el alta médica cuando no se mantengan las condiciones epidemiológicas y clínicas que dieron lugar a la emisión de este tipo de partes de baja.

Procedimiento de actuación para los servicios de prevención de riesgos laborales frente a la exposición al SARS-CoV-2, 8 de junio de $\mathbf{2 0}^{(8)}$. Incorporación novedad legislativa: consideración de la COVID-19 como accidente de trabajo. Modelo de informe para la comunicación del SPRL a la Mutua colaboradora de la Seguridad Social.

En el Anexo I, del citado procedimiento, se aporta modelo de informe para la acreditación por parte del servicio de prevención:

1. Caso sospechoso, confirmado o contacto estrecho

2. Especial sensibilidad. necesidad de IT

3. Especial sensibilidad. No hay necesidad de IT

4. Informe para la mutua para la valoración de contingencia profesional derivada de accidente de trabajo

Procedimiento de actuación para los servicios de prevención de riesgos laborales frente a la exposición al SARS-CoV-2 19$^{(9)}$. Fija estos escenarios de riesgo de exposición al coronavirus SARS-CoV-2 en el entorno laboral (Cuadro 1).

Cuadro 1: Escenarios de riesgo de exposición al coronavirus.

\begin{tabular}{|c|c|c|}
\hline EXPOSICIÓN DE RIESGO & EXPOSICIÓN DE BAJO RIESGO & $\begin{array}{l}\text { BAJA PROBABILIDAD DE EXPO- } \\
\text { SICIÓN }\end{array}$ \\
\hline $\begin{array}{l}\text { Personal sanitario asistencial y no } \\
\text { asistencial que atiende a casos } \\
\text { sospechosos o confirmados de } \\
\text { COVID-19. } \\
\text { Situaciones en las que no se puede } \\
\text { evitar el contacto estrecho en el } \\
\text { trabajo con casos sospechosos o } \\
\text { confirmados de COVID-19. }\end{array}$ & $\begin{array}{l}\text { Personal asistencial y no asistencial } \\
\text { que entra en zonas COVID, y cuyas } \\
\text { tareas se realizan manteniendo la } \\
\text { distancia de seguridad y sin actua- } \\
\text { ción directa sobre casos sospecho- } \\
\text { sos o confirmados. } \\
\text { Personal no sanitario que tenga } \\
\text { contacto con material sanitario, } \\
\text { fómites o desechos posiblemente } \\
\text { contaminados. } \\
\text { Ayuda a domicilio de contactos } \\
\text { asintomáticos. }\end{array}$ & $\begin{array}{l}\text { Personal sanitario asistencial y } \\
\text { no asistencial que desarrolla su } \\
\text { actividad en áreas NO COVID con las } \\
\text { medidas de prevención adecuadas. } \\
\text { Trabajo en ámbito no sanitario o no } \\
\text { sociosanitario con probabilidad de } \\
\text { contacto con casos de COVID-19, } \\
\text { manteniendo la distancia de segu- } \\
\text { ridad y sin actuación directa sobre } \\
\text { ellos }\end{array}$ \\
\hline
\end{tabular}




\subsubsection{Situaciones protegidas}

La prolija normativa e instrucciones antes referidas definen tres situaciones de IT COVID-19:

- IT por aislamiento, sospecha o contacto

- IT supuestos de confinamiento total de trabajadores esenciales

- IT por infección

- IT trabajador especialmente sensible

2.1.3. Códigos partes de baja COVID-19

Se establecieron los códigos CIE 9 CIE 10 a incluir en los partes de baja para cada situación. Aislamiento por contacto o exposición

CIE 10 ES: Z20.828_Contacto y exposición (sospechada) a otras enfermedades transmisibles virales. CIE-9-MC: V01.79_Exposición a otras enfermedades víricas (Coronavirus diferentes SARS- CoV) Infección contagio

CIE 10 ES: B34.2 Infección debida a coronavirus, no especificada.

CIE-9-MC: 079.82 Infección por coronavirus asociado a SARS.

Solo deben codificarse como COVID-19 los diagnósticos confirmados que hayan sido constatados por el clínico o por la presencia documental de una prueba con resultado positivo a COVID-19. En los casos confirmados, asigne el código U07.1 COVID-19.

\section{Trabajador sensible}

CIE 10 ES: Z29.8 (contacto para otras medidas profilácticas especificadas).

CIE-9-MC: V07.8 (otra medida profiláctica o terapéutica especificada).

Confinamiento total obligado (zonas geográficas, poblaciones o áreas de una población que en un momento dado quedan confinadas)

CIE 10 ES: Z20.828 Contacto y exposición (sospechada) a otras enfermedades transmisibles virales

CIE-9-MC: V01.79 Exposición a otras enfermedades víricas (Coronavirus diferentes SARS- CoV)

\subsection{El nuevo concepto de la IT COVID-19, la consideración preventiva ${ }^{(10,11)}$}

Las novedades de la Incapacidad Temporal por COVID-19 más relevantes son la protección del aislamiento por sospecha o contacto, el «confinamiento total», la colaboración de los servicios de prevención con atención primaria en supuestos laborales, la mayor dotación económica de la prestación y la extensión de los partes por COVID-19 de forma telemática.

2.2.1. Carácter preventivo de la protección de la salud pública, mediante la prestación de Incapacidad Temporal.

En la IT Covid-19 hay una expansión de la protección de las situaciones de IT, trascendiendo más allá de la protección de la pérdida de la salud individual y abarcando la protección de la pérdida de la salud pública. Así mismo conlleva la colaboración de los servicios de prevención en la mayor certeza la toma de decisiones de las situaciones de incapacidad laboral que compete a los Servicios Públicos, en lo concerniente a los procesos con relación laboral (contacto, trabajador sensible o infección).

- Consideración como Incapacidad Temporal de los periodos de «aislamiento preventivo». Se amplía el concepto de «protección de la IT», que sólo protege situaciones debidas a enfermedad, mientras el trabajador reciba asistencia sanitaria y esté impedido para el trabajo. En el aislamiento no se está enfermo, no se precisa asistencia sanitaria ni se han perdido facultades o se presentan limitaciones funcionales que impidan trabajar.

Antecedentes: De forma excepcional ya la Resolución de 7 de mayo de 2009, de la Dirección General de Ordenación de la Seguridad Social, consideró como situación de Incapacidad Temporal derivada 
de enfermedad común de los períodos de Aislamiento Preventivo sufridos por los trabajadores como consecuencia de la Gripe A H1 N1.

- Así mismo se dota de carácter preventivo la Incapacidad Temporal de las situaciones de «confinamiento total» u obligado confinamiento (Real Decreto-ley 11/2020, de 31 de marzo). Trabajadores por cuenta ajena o por cuenta propia obligados a desplazarse de localidad y con obligación de prestar servicios esenciales que no puedan hacerlo debido al confinamiento de la población en la que viven y siempre que les haya sido denegada la posibilidad de desplazarse por la autoridad competente, no puedan realizar su trabajo de manera telemática y no tengan derecho a percibir otra prestación pública.

- Carácter preventivo en la consideración de situación de Incapacidad Temporal de Trabajadores Vulnerables o Sensibles al COVID-19, cuando a pesar de las medidas de prevención, adaptación y protección establecidas, su precario estado de salud y las condiciones de trabajo no les permitan trabajar sin un considerable y estimado riesgo para su salud.

\subsubsection{Mayor prestación económica}

Tanto la situación de Incapacidad Temporal por aislamiento preventivo como la Incapacidad Temporal por contagio con Coronavirus se asimilan a accidente de trabajo exclusivamente en cuanto a la prestación económica.

- Al considerarse la prestación económica de la baja, de forma excepcional como accidente de trabajo, a los exclusivos efectos económicos, se percibe el $75 \%$ de la base reguladora desde el día siguiente a baja, el día de la baja corresponde su pago a la empresa y no se exigen 180 días de cotizaciones previas («carencia»); frente a lo que debiera percibir si se considerara una enfermedad (común), no cobrar el trabajador los 3 primeros días de baja, del $4^{\circ}$ al $20^{\circ}$ percibir el $60 \%$, y desde el $21^{\circ}$ el $75 \%$, y el abono del $4^{\circ}$ al $15^{\circ}$ corresponder a la empresa.

- Con esta consideración de accidente el pago corresponde a la Mutua, aunque la asistencia y la extensión de partes de baja y alta corresponde al Servicio Público de Salud como enfermedad común.

\subsection{La contingencia}

\subsubsection{Contingencia genérica}

El artículo quinto del Real Decreto-ley 6/2020, de 10 de marzo, modificado por Real Decreto-ley 13/2020, de 7 de abril, establece lo siguiente:

Al objeto de proteger la salud pública, se considerarán, con carácter excepcional, situación asimilada a accidente de trabajo, exclusivamente para la prestación económica de incapacidad temporal del sistema de Seguridad Social, aquellos periodos de aislamiento o contagio de las personas trabajadoras provocados por el virus COVID-19, salvo que se pruebe que el contagio de la enfermedad se ha contraído con causa exclusiva en la realización del trabajo en los términos que señala el artículo 156 del texto refundido de la Ley General de la Seguridad Social, en cuyo caso será calificada como accidente de trabajo.

Es decir, se prevé una regla general, que es la asimilación a los exclusivos efectos económicos de la IT como AT de aquellos periodos de aislamiento o contagio de las personas trabajadoras provocados por el virus COVID-19, siendo la contingencia señalada en el parte de baja como enfermedad común y respondiendo de la asistencia el Servicio Público de Salud que no la mutua (que sí es la que paga).

Junto a dicha regla general, se prevé la posibilidad de que se acredite que el contagio se ha contraído en el trabajo, y este sea la «causa exclusiva» del mismo, en cuyo caso, será calificada como accidente de trabajo a todos los efectos y sin referirse a ocupaciones concretas.

\subsubsection{Contingencia para el personal sanitario y sociosanitario}

El artículo quinto del Real Decreto-ley 6/2020, de 10 de marzo, modificado por Real Decreto-ley 13/2020, de 7 de abril, establece lo siguiente: 


\section{Consideración de AT del personal sanitario y sociosanitario.}

Real Decreto-ley 19/2020, de 26 de mayo, prevé en su artículo 9 que: Las prestaciones de Seguridad Social que cause el personal que presta servicios en centros sanitarios o socio-sanitarios, inscritos en los registros correspondientes, y que en el ejercicio de su profesión, hayan contraído el virus SARS-CoV2 durante cualquiera de las fases de la epidemia, por haber estado expuesto a ese riesgo específico durante la prestación de servicios sanitarios y socio-sanitarios, cuando así se acredite por los servicios de Prevención de Riesgos laborales y Salud Laboral, se considerarán derivadas de accidente de trabajo, al entender cumplidos los requisitos exigidos en el artículo 156.2.e) del texto refundido de la Ley General de la Seguridad Social.

El Real Decreto-ley 27/2020, de 4 de agosto, prorroga la consideración como contingencia profesional derivada de accidente de trabajo, de las enfermedades padecidas por el personal que presta servicio en centros sanitarios o sociosanitarios como consecuencia del contagio del virus SARS-CoV2, hasta que las autoridades sanitarias decreten el levantamiento de todas las medidas de prevención adoptadas para hacer frente a esta crisis sanitaria.

Esta norma tiene un carácter excepcional que atañe a la temporalidad de la medida, hasta que concluyan las medidas de prevención frente a la crisis sanitaria y a que la asistencia sanitaria será prestada de forma excepcional como contingencia común, por el servicio público de salud y no con cargo a la mutua, que sería la norma general. El contagio y padecimiento de la enfermedad se acreditará mediante el correspondiente parte de accidente de trabajo que deberá haberse expedido dentro del mismo periodo de referencia.

Consideración de Enfermedad Profesional del personal sanitario y sociosanitario, sólo a efectos de la prestación.

El Real Decreto-ley 3/2021, de 2 de febrero, establece en su artículo 6 que las «prestaciones» causadas por las y los profesionales de centros sanitarios y socio sanitarios que durante la prestación de servicios sanitarios o socio sanitarios han contraído el virus SARS-CoV-2 en el ejercicio de su profesión serán las mismas que el sistema de la Seguridad Social otorga a quienes hubieran contraído una enfermedad profesional. Se trata, con ello, de dar una respuesta excepcional a una situación también excepcional. La excepcionalidad atañe a la temporalidad de la medida, hasta que concluyan las medidas de prevención frente a la crisis sanitaria y sólo a los «efectos prestacionales». NO SUPONE la asunción de la CONTINGENCIA COMO ENFERMEDAD PROFESIONAL.

\subsubsection{Contingencia a aplicar a las bajas por COVID-19 según la norma actual}

Contingencia no profesional (enfermedad común) en supuestos de IT por aislamiento o contagio de las personas trabajadoras provocados por el virus COVID-19 sin acreditada relación laboral causal.

Contingencia de accidente de trabajo en supuestos de IT por aislamiento o contagio de las personas trabajadoras provocados por el virus COVID-19 cuando se pruebe que el contagio de la enfermedad se ha contraído con causa exclusiva en la realización del trabajo.

Contingencia de accidente de trabajo en supuestos de IT por aislamiento o contagio de las provocados por el virus COVID-19 que cause el personal que presta servicios en centros sanitarios o socio-sanitarios, inscritos en los registros correspondientes, y que en el ejercicio de su profesión, hayan contraído el virus SARS-CoV2 durante cualquiera de las fases de la epidemia, por haber estado expuesto a ese riesgo específico durante la prestación de servicios sanitarios y socio-sanitarios, cuando así se acredite por los servicios de Prevención de Riesgos laborales y Salud Laboral.

\subsubsection{Discusión sobre la contingencia de la IT COVID-19}

COVID-19 como accidente de trabajo (AT).

De forma genérica la enfermedad por Coronavirus SARS-CoV-2, podría ser considerada como laboral, como accidente de trabajo, según artículo 156 e) LGSS, que posibilita la inclusión de enfermedades, no incluidas como Enfermedad Profesional, como AT, cuando el trabajador la contraiga con motivo de la realización de su trabajo, siempre que se pruebe que la enfermedad tuvo por causa exclusiva la ejecu- 
ción del mismo. En la actual situación de pandemia, tendría esta consideración de accidente de trabajo, los contagios «accidentales» sobrevenidos en la prestación del trabajo. Se precisaría probar que se ha contraído la enfermedad tras prestar un trabajo a persona contagiada, excluyendo otro contagio ajeno al trabajo prestado. Se trata siempre de una situación en la que hay que probar los hechos, pero en las circunstancias actuales esta «probanza» sería más bien en tanto no se demostrara lo contrario, lo que no siempre es una situación pacífica, puede afectar a actividades muy diversas, en las que se presume se ha contraído la enfermedad de forma accidental u ocasional.

La estimación de Accidente de trabajo afectaría a trabajadores en los que este riesgo de contagio no está previsto en la evaluación de riesgos de su puesto de trabajo, pues no hay riesgo de exposición habitual en su puesto de trabajo, y se ha contraído la enfermedad con carácter accidental por contagio prestando el trabajo, lo que no es el caso del personal sanitario.

\section{Contingencia de Accidente de Trabajo IT COVID-19 para personal sanitario y sociosanitario}

Es la actual consideración expresa para este personal, según la norma. Se entiende como personal sanitario y sociosanitario el que presta atención sanitaria o sociosanitaria o realiza servicios sanitarios o sociosanitarios, pero la indefinición normativa excluiría otro personal que trabajando en centros sanitarios o socio-sanitarios desempeñe otras funciones distintas a la prestación de servicios sanitarios y socio-sanitarios caso del personal de gestión, administrativo, de mantenimiento, de limpieza, vigilantes, celadores, etc.

En cuanto a actividades sanitarias o sociosanitarias en centros sanitarios, no se concreta en la norma que centros son y cuáles podrían ser excluidas, por tanto, esto queda a valoración. Se entiende que indubitadamente son centros sanitarios o socio-sanitarios los centros dedicados a actividades comprendidas en el Grupo Q («actividades sanitarias y de servicios sociales») de la CNAE, y de ellas las que se enumeran en la división 86 «actividades sanitarias», (los técnicos de emergencias sanitarias CNAE 8690 quedarían incluidos); y dentro de la división 87 solo recogería los del grupo 87.1 («Asistencia en establecimientos residenciales con cuidados sanitarios»). Pero de ser así quedan excluidos los centros dedicados al resto de actividades relacionadas en el Grupo Q, como son los centros de asistencia en establecimientos residenciales para personas con discapacidad intelectual, enfermedad mental y drogodependencia 87.20, los centros de asistencia en establecimientos residenciales para personas mayores y con discapacidad física 87.3 los centros de asistencia en establecimientos residenciales para personas mayores 87.31 , establecimientos residenciales para personas con discapacidad física 87.32 o los centros de actividades de servicios sociales sin alojamiento para personas mayores y con discapacidad 88.1; así como otros tipos de centros como los dedicados a pompas fúnebres y actividades relacionadas CNAE 9603, o al comercio al por menor de productos farmacéuticos en establecimientos especializados, CNAE 4773, que se incluyen en Grupo G.

\subsubsection{COVID-19 como Enfermedad Profesional en personal sanitario y sociosanitario una cuestión no resuelta}

Para la consideración de una enfermedad como Profesional se requiere que la enfermedad se contraiga a consecuencia del trabajo ejecutado en las actividades que se especifiquen en el cuadro de enfermedades profesionales y que esté provocada por la acción de los elementos que en dicho cuadro se indiquen para cada enfermedad profesional. LGSS artículo 157. La enfermedad profesional es un «constructo legal», es decir, una construcción legal o normativa que configura, delimita y concreta lo qué es enfermedad profesional en base al artículo 157 LGSS que establece su concepto y al Real Decreto 1299/2006 que aprueba el Cuadro de Enfermedades Profesionales. El cuadro de Enfermedad Profesional está construido sobre el riesgo de exposición a agentes causales presentes en las tareas o actividades donde haya riesgo de exposición; en el caso que nos ocupa la infección por agentes biológicos, con evidente exposición al riesgo de contagio. Nuestra lista de enfermedades profesionales es una lista cerrada a determinados agentes causales, pero imprecisa o muy sintética de actividades.

Para la concreción de la Enfermedad Profesional se requieren tres requisitos presentes, concurrentes:

- Una enfermedad recogida en el listado 
- Un riesgo probado de exposición al agente causal específico para esa enfermedad

- Y una profesión con actividades en las que se está expuesto a dicho riesgo causante de la enfermedad.

La infección por COVID-19 «Coronavirus» está incluida en el Cuadro de Enfermedades Profesionales como enfermedad profesional causada por agentes biológicos y recogida la actividad del personal sanitario y otros, como colectivo laboral de riesgo a la infección. El Grupo 3, Apartado A Agentes Infecciosos recoge las enfermedades infecciosas causadas por el trabajo de las personas que se ocupan de la prevención, asistencia médica y actividades en las que se ha probado un riesgo de infección, inclusión debida en este apartado, pues el virus SARS-CoV- 2 pertenece a la familia Coronaviridae, que en el anexo Il del RD 664/1997 aparecía clasificada en el grupo 2, mal clasificada, pues debiera de incluirse en el grupo 3 atendiendo a criterios legales y técnicos, clasificación ahora elevada al grupo 3 según Orden TES/1180/2020, de 4 de diciembre y explícitamente referida al SARS-CoV-2. (Grupo 3 de la clasificación de agentes biológicos que alude a agentes biológicos que pueden causar una enfermedad grave en el hombre y presenta un serio peligro para los trabajadores, con riesgo de que se propague a la colectividad). A mayor abundamiento el personal laboral sanitario y sociosanitarios ha sido el colectivo laboral más afectado, no en vano el de más riesgo de contagio.

Concluyendo: la infección por infección por SARS-CoV-2 COVID-19, está recogida como Enfermedad Profesional en el actual listado Grupo 3 como Enfermedad Profesional causada por Agentes Biológicos, las actividades sanitarias se recogen como actividades con exposición al riesgo de contagio a dicho agente causal, por lo que, si se ha contraído la enfermedad a consecuencia de ejecutar el trabajo, esta debe corresponder a la contingencia de Enfermedad Profesional.

Por todo lo cual el COVID-19 (infección por SARS-CoV-2) del personal sanitario y sociosanitario a consecuencia de su trabajo está incluido en el cuadro de Enfermedades Profesionales, y es un derecho incuestionable a reparar. Configurando la presunción «iuris et de iure», no admitiendo prueba en contrario, por darse el «constructo legal» de ser enfermedad causada a consecuencia del trabajo y estar incluida la misma en el cuadro de enfermedad profesional ${ }^{(12)}$.

La consideración de la OMS de enfermedad profesional trabajadores de la salud ${ }^{(13)}$.

La OMS, el 19 marzo 2020, establecía que se debe considerar el derecho a compensación, rehabilitación y servicios curativos para trabajadores de la salud infectados con COVID-19 después de la exposición en el lugar de trabajo «considerada como una enfermedad profesional derivada de exposición ocupacional».

¿Qué supone la declaración de la Incapacidad Laboral por «Coronavirus» COVID-19 como Enfermedad Profesional?

La consideración de enfermedad profesional comparte con el accidente la cuantía de la prestación económica, la responsabilidad de la mutua en su asistencia sanitaria y el recargo de prestaciones por falta de medidas de seguridad e higiene, establecidas en el artículo 164 de la LGSS.

Recargo de prestaciones de las prestaciones por Accidente de Trabajo o Enfermedad Profesional. Articulo 164 LGSS1.

Todas las prestaciones económicas que tengan su causa en accidente de trabajo o enfermedad profesional se aumentarán, según la gravedad de la falta, de un 30 a un 50 por ciento, cuando la infección se produzca por causa de equipos de trabajo deficientes o actividades en centros o lugares de trabajo que carezcan de los medios de protección reglamentarios, o en malas condiciones, o cuando no se hayan observado las medidas generales o particulares de seguridad y salud en el trabajo, o las de adecuación personal a cada trabajo, habida cuenta de sus características y de la edad, sexo y demás condiciones del trabajador.

La responsabilidad del pago del recargo establecido recaerá directamente sobre el empresario o institución sanitaria infractora y no podrá ser objeto de seguro alguno, siendo nulo de pleno derecho cualquier pacto o contrato que se realice para cubrirla, compensarla o trasmitirla. Esta responsabilidad es independiente y compatible con las de todo orden, incluso penal, que puedan derivarse de la infracción. 
Diferencias entre la consideración del «Coronavirus COVID-19» como accidente de trabajo o como enfermedad profesional.

- El periodo de aislamiento pasaría a ser considerado como periodo de observación de enfermedad profesional.

- La imprescriptibilidad de su reconocimiento, que es posible en cualquier momento posterior a los sucesos que dieran lugar a la declaración de tal contingencia, incluso superando la edad de jubilación, lo que no sucede en el Accidente de Trabajo. La imprescriptibilidad daría lugar a la compensación como enfermedad profesional de las secuelas que pudieran sobrevenir en un futuro, derivadas de haber padecido la enfermedad cuyo curso clínico evolutivo es imprevisible.

- La puesta en marcha del escudo de protección en actuaciones obligadas de vigilancia de la salud por parte de la empresa, lo que no sucede cuando se considera un proceso debido a accidente de trabajo.

\section{La incapacidad temporal laboral en los tiempos del COVID-19}

\subsection{La incapacidad temporal en el confinamiento y la desescalada}

Declarada la pandemia el 11 de marzo por la OMS, se sucedió en España la declaración del estado de alarma el 14 de marzo con el confinamiento de la población, excepción hecha de los trabajadores en trabajos esenciales, y no fue hasta el final de abril cuando comienza la desescalada; intento de retorno a la normalidad que no se consolidaría hasta entrado junio.

Analicemos los datos de la IT durante estos meses marzo, abril, mayo y junio de 2020, que abarcan el confinamiento y la desescalada. El dato más relevante es la escalada en la duración media de los procesos. Durante el periodo del «confinamiento» y la «desescalada» la duración de la incapacidad temporal se incrementó en un $84,48 \%$. (Tabla 1; Tabla 2)

En procesos habitualmente más largos de incapacidad temporal, reseñar el incremento del $34,12 \%$ de la duración media de las neoplasias, el 29,56\% de los trastornos mentales, el 33,37\% de las enfermedades cardiovasculares, el 45;42\% de las enfermedades de la sangre, el 31,94\% de los "procedimientos», el $35,63 \%$ de la duración media de los trastornos osteomioarticulares, el incremento del $60,73 \%$ de la duración de las enfermedades endocrinas, de la nutrición y metabólicas, el incremento del 45,09\% de las enfermedades digestivas. El incremento desproporcionado de la duración media en las enfermedades respiratorias del 503,58\%, o en las enfermedades infecciosas $215,88 \%$, los códigos V $149,19 \%$, está en relación estrecha con los procesos Covid. La Tabla 1 recoge la duración media ordenada de mayor a menor por capítulos diagnósticos y la variación porcentual producida en junio.

Tabla 1: Comparativa duración media IT marzo y junio, y variación \%.

\begin{tabular}{|c|c|c|c|c|}
\hline Capítulo de diagnóstico & $\begin{array}{c}\text { Duración } \\
\text { media } \\
\text { marzo }\end{array}$ & Capítulo de diagnóstico & $\begin{array}{c}\text { Duración } \\
\text { media } \\
\text { junio }\end{array}$ & $\begin{array}{l}\text { \% Variación } \\
\text { junio-marzo }\end{array}$ \\
\hline Neoplasias & 81,09 & Neoplasias & 108,76 & 34,12 \\
\hline CÓDIGOS MIL & 76,11 & Trastornos mentales & 89,67 & 29,56 \\
\hline Trastornos mentales & 69,21 & $\begin{array}{l}\text { Enfermedades del sistema circu- } \\
\text { latorio }\end{array}$ & 87,47 & 33,37 \\
\hline $\begin{array}{l}\text { Enfermedades del sistema } \\
\text { circulatorio }\end{array}$ & 65,58 & Anomalías congénitas & 85,79 & 54,96 \\
\hline $\begin{array}{l}\text { Enfermedades con origen en } \\
\text { periodo perinatal }\end{array}$ & 63,78 & $\begin{array}{l}\text { Enfermedades de la sangre y órga- } \\
\text { nos hematopoyéticos }\end{array}$ & 84,07 & 45,42 \\
\hline $\begin{array}{l}\text { Complicaciones del embara- } \\
\text { zo, parto y puerperio }\end{array}$ & 61,78 & CÓDIGOS MIL & 83,07 & 9,14 \\
\hline PROCEDIMIENTOS & 59,36 & $\begin{array}{l}\text { Complicaciones del embarazo, parto } \\
\text { y puerperio }\end{array}$ & 81,19 & 31,41 \\
\hline
\end{tabular}




\begin{tabular}{|c|c|c|c|c|}
\hline Capítulo de diagnóstico & $\begin{array}{l}\text { Duración } \\
\text { media } \\
\text { marzo }\end{array}$ & Capítulo de diagnóstico & $\begin{array}{c}\text { Duración } \\
\text { media } \\
\text { junio }\end{array}$ & $\begin{array}{l}\text { \% Variación } \\
\text { junio-marzo }\end{array}$ \\
\hline $\begin{array}{l}\text { Enfermedades de la sangre y } \\
\text { órganos hematopoyéticos }\end{array}$ & 57,81 & PROCEDIMIENTOS & 78,32 & 31,94 \\
\hline Anomalías congénitas & 55,36 & $\begin{array}{l}\text { Enfermedades con origen en periodo } \\
\text { perinatal }\end{array}$ & 72,37 & 13,46 \\
\hline $\begin{array}{l}\text { Enfermedades del siste- } \\
\text { ma osteomioarticular y } \\
\text { conectivo }\end{array}$ & 49,34 & Sin diagnóstico & 70,30 & 49,11 \\
\hline Lesiones y envenenamiento & 43,90 & $\begin{array}{l}\text { Enfermedades del sistema osteo- } \\
\text { mioarticular y conectivo }\end{array}$ & 66,92 & 35,63 \\
\hline $\begin{array}{l}\text { C. Endocrinas, de la nu- } \\
\text { trición, metabólicas y T. } \\
\text { inmunidad }\end{array}$ & 41,56 & $\begin{array}{l}\text { C. Endocrinas, de la nutrición, } \\
\text { metabólicas y T. inmunidad }\end{array}$ & 66,80 & 60,73 \\
\hline CÓDIGOS E & 38,40 & Lesiones y envenenamiento & 57,23 & 30,36 \\
\hline $\begin{array}{l}\text { Enfermedades del SNC y } \\
\text { órganos de los sentidos }\end{array}$ & 31,92 & $\begin{array}{l}\text { Enfermedades del SNC y órganos } \\
\text { de los sentidos }\end{array}$ & 47,91 & 50,09 \\
\hline $\begin{array}{l}\text { Enfermedades del aparato } \\
\text { genitourinario }\end{array}$ & 30,15 & $\begin{array}{l}\text { Enfermedades del sistema respi- } \\
\text { ratorio }\end{array}$ & 47,14 & 503,58 \\
\hline Sin diagnóstico & 28,22 & CÓDIGOS E & 47,23 & 22,99 \\
\hline $\begin{array}{l}\text { Enfermedades de la piel y } \\
\text { del tejido subcutáneo }\end{array}$ & 26,49 & $\begin{array}{l}\text { Enfermedades del aparato genitou- } \\
\text { rinario }\end{array}$ & 40,43 & 34,09 \\
\hline $\begin{array}{l}\text { Enfermedades del sistema } \\
\text { digestivo }\end{array}$ & 24,37 & CóDIGOS V & 40,42 & 149,19 \\
\hline CÓDIGOS V & 16,22 & $\begin{array}{l}\text { Enfermedades de la piel y del teji- } \\
\text { do subcutáneo }\end{array}$ & 36,83 & 39,03 \\
\hline $\begin{array}{l}\text { Síntomas, signos y estados } \\
\text { mal definidos }\end{array}$ & 15,63 & $\begin{array}{l}\text { Enfermedades del sistema diges- } \\
\text { tivo }\end{array}$ & 35,36 & 45,09 \\
\hline $\begin{array}{l}\text { Enfermedades del sistema } \\
\text { respiratorio }\end{array}$ & 7,81 & $\begin{array}{l}\text { Síntomas, signos y estados mal } \\
\text { definidos }\end{array}$ & 33,40 & 113,69 \\
\hline $\begin{array}{l}\text { Enfermedades infecciosas y } \\
\text { parasitarias }\end{array}$ & 6,36 & $\begin{array}{l}\text { Enfermedades infecciosas y para- } \\
\text { sitarias }\end{array}$ & 20,09 & 215,88 \\
\hline Total & 29,77 & Total & 54,92 & 84,48 \\
\hline
\end{tabular}

En cuanto al número de procesos este descendió a lo largo de este periodo en un 31,47\%, por una razón elemental: durante este periodo la población trabajadora susceptible de precisar IT descendió, una parte de la población trabajadora trabajaba en teletrabajo, hubo pase a desempleo, se sucedieron Ios ERTES, y una parte de la población trabajadora pudo estar en situación de permiso por conciliación o de una u otra forma durante un tiempo estaba sin necesidad de trabajar por cierre de la actividad presencial; la propia tramitación de la IT NO COVID no era fácil, pues durante un tiempo los centros de salud estaban cerrados a esta actividad, considerada como no esencial clínica, ni prioritaria en plena pandemia. También conviene precisar que se inició un aluvión de IT's por COVID en sus tres formas esenciales, infección, contacto-aislamiento o trabajador sensible. En la Tabla recogemos el número de procesos en marzo y junio ordenados de mayor a menor y la variabilidad porcentual en junio.

Es llamativo que, frente al descenso generalizado, de las bajas, comparando procesos en marzo y en junio, las enfermedades endocrinas, metabólicas o de la nutrición se incrementaron en un 40\%, los trastornos mentales tuvieron un incremento del $13,46 \%$, las enfermedades de la sangre se incrementaron en un $9,24 \%$, las enfermedades cardiovasculares se incrementaron en un $7,38 \%$. Los aumentos en los códigos V del 64,40\% guardan relación estrecha con el COVID. En cuanto al descenso significativo de las enfermedades respiratorias, del $85,20 \%$ la explicación probable lo sea por motivos de calificación diagnóstica en los partes de baja, diferente al inicio del confinamiento y las nuevas instrucciones sobre 
los códigos diagnósticos guardan del COVID. El descenso de los «procedimientos» del 26,09\% es debido a la anulación de intervenciones programadas no urgentes y el incremento de las listas de espera.

Tabla 2: Comparativa $n^{\circ}$ de procesos meses marzo y junio 2020.

\begin{tabular}{|c|c|c|c|c|}
\hline Capítulo de diagnóstico & $\begin{array}{l}\text { Número de } \\
\text { procesos } \\
\text { Marzo }\end{array}$ & Capítulo de diagnóstico & $\begin{array}{l}\text { Número de } \\
\text { procesos } \\
\text { Junio }\end{array}$ & $\begin{array}{l}\text { \% Variación } \\
\text { junio-marzo }\end{array}$ \\
\hline $\begin{array}{l}\text { Enfermedades del sistema } \\
\text { respiratorio }\end{array}$ & 114.722 & $\begin{array}{l}\text { Enfermedades del sistema } \\
\text { osteomioarticular y conectivo }\end{array}$ & 86.341 & $-13,07$ \\
\hline $\begin{array}{l}\text { Enfermedades del sistema os- } \\
\text { teomioarticular y conectivo }\end{array}$ & 100.047 & Lesiones y envenenamiento & 46.613 & $-14,51$ \\
\hline $\begin{array}{l}\text { Síntomas, signos y estados mal } \\
\text { definidos }\end{array}$ & 68.162 & $\begin{array}{l}\text { Síntomas, signos y estados } \\
\text { mal definidos }\end{array}$ & 43.239 & $-36,57$ \\
\hline $\begin{array}{l}\text { Enfermedades infecciosas y } \\
\text { parasitarias }\end{array}$ & 43.379 & Trastornos mentales & 29.189 & 13,46 \\
\hline Lesiones y envenenamiento & 54.521 & CóDIGOS V & 27.537 & 64,20 \\
\hline $\begin{array}{l}\text { Enfermedades del sistema } \\
\text { digestivo }\end{array}$ & 27.111 & $\begin{array}{l}\text { Enfermedades infecciosas y } \\
\text { parasitarias }\end{array}$ & 26.677 & $-38,51$ \\
\hline Trastornos mentales & 25.725 & $\begin{array}{l}\text { Enfermedades del sistema } \\
\text { digestivo }\end{array}$ & 20.477 & $-24,47$ \\
\hline $\begin{array}{l}\text { Enfermedades del SNC y órga- } \\
\text { nos de los sentidos }\end{array}$ & 23.218 & $\begin{array}{l}\text { Enfermedades del SNC y órga- } \\
\text { nos de los sentidos }\end{array}$ & 18.167 & $-21,76$ \\
\hline $\begin{array}{l}\text { Enfermedades del aparato } \\
\text { genitourinario }\end{array}$ & 11.088 & $\begin{array}{l}\text { Enfermedades del sistema } \\
\text { respiratorio }\end{array}$ & 16.987 & $-85,20$ \\
\hline CÓDIGOS V & 16.770 & $\begin{array}{l}\text { Enfermedades del sistema } \\
\text { circulatorio }\end{array}$ & 9.144 & 7,38 \\
\hline $\begin{array}{l}\text { Enfermedades del sistema } \\
\text { circulatorio }\end{array}$ & 8.515 & $\begin{array}{l}\text { Enfermedades del aparato } \\
\text { genitourinario }\end{array}$ & 9.036 & $-18,51$ \\
\hline Neoplasias & 7.194 & Neoplasias & 6.609 & $-8,14$ \\
\hline $\begin{array}{l}\text { Complicaciones del embarazo, } \\
\text { parto y puerperio }\end{array}$ & 5.908 & $\begin{array}{l}\text { Complicaciones del embarazo, } \\
\text { parto y puerperio }\end{array}$ & 5.041 & $-14,68$ \\
\hline $\begin{array}{l}\text { Enfermedades de la piel y del } \\
\text { tejido subcutáneo }\end{array}$ & 5.902 & $\begin{array}{l}\text { Enfermedades de la piel y del } \\
\text { tejido subcutáneo }\end{array}$ & 4.915 & $-14,59$ \\
\hline PROCEDIMIENTOS & 5.551 & PROCEDIMIENTOS & 4.103 & $-26,09$ \\
\hline Sin diagnóstico & 3.943 & $\begin{array}{l}\text { C. Endocrinas, de la nu- } \\
\text { trición, metabólicas y T. } \\
\text { inmunidad }\end{array}$ & 3.103 & 40,00 \\
\hline $\begin{array}{l}\text { C. Endocrinas, de la nutrición, } \\
\text { metabólicas y T. inmunidad }\end{array}$ & 2.152 & Sin diagnóstico & 1.343 & 65,94 \\
\hline $\begin{array}{l}\text { Enfermedades de la sangre y } \\
\text { órganos hematopoyéticos }\end{array}$ & 649 & $\begin{array}{l}\text { Enfermedades de la sangre y } \\
\text { órganos hematopoyéticos }\end{array}$ & 709 & 9,24 \\
\hline Anomalías congénitas & 601 & Anomalías congénitas & 555 & $-7,66$ \\
\hline CÓDIGOSE & 200 & CÓDIGOSE & 200 & 0,00 \\
\hline CÓDIGOS MIL & 154 & CÓDIGOS MIL & 154 & 0,00 \\
\hline $\begin{array}{l}\text { Enfermedades con origen en } \\
\text { periodo perinatal }\end{array}$ & 94 & $\begin{array}{l}\text { Enfermedades con origen en } \\
\text { periodo perinatal }\end{array}$ & 62 & 34,05 \\
\hline Total & 525.606 & Total & 360.201 & $-31,47$ \\
\hline
\end{tabular}




\subsection{La incapacidad temporal en la vuelta a la normalidad, la nueva realidad}

Nos centraremos en el análisis de los datos de IT acumulados a octubre 2020, pues así recogemos periodo crítico de la primera ola, la mal llamada «nueva normalidad», mejor calificada como nueva realidad, y el momento final de la primera ola, antes de la segunda ola de noviembre.

\section{Comparativa IT por capítulo diagnósticos acumulada a octubre 2019 y a octubre 2020}

En la comparación de la duración media de la IT acumulada a octubre 2020 comparada con la del año anterior (Tabla 3), la duración de la IT subió un 12,09\% es decir arrastra el efecto de los meses del confinamiento, en los que la IT alcanzó una duración media del 84,48. Por capítulos diagnósticos destacar que en procesos como las neoplasias con incapacidades temporales habitualmente largas se incrementó su duración media un 3,58\%, y lo mismo para los trastornos mentales tuvieron un incremento de su duración media del 15,89\%, los trastorno osteomioarticulares se incrementó su duración en un $16,71 \%$, y las enfermedades del sistema circulatorio tuvieron una duración incrementada del 8,67\%. En cuanto a valores absolutos del crecimiento porcentual a destacar el incremento del $149,71 \%$ de la duración media de las enfermedades infecciosas, el 48,19\% de las enfermedades respiratorias, el $31,72 \%$ de las enfermedades digestivas o el incremento de la duración media del $25,08 \%$ de los «procedimientos».

Tabla 3: Comparativa de la duración media 20192020 acumulada a octubre.

\begin{tabular}{|c|c|c|c|}
\hline Capítulo de diagnóstico & $\begin{array}{c}\text { Duración } \\
\text { media } \\
2019\end{array}$ & $\begin{array}{c}\text { Duración } \\
\text { media } \\
2020\end{array}$ & $\begin{array}{l}\text { \% diferencia } \\
\text { interanual }\end{array}$ \\
\hline Enfermedades infecciosas y parasitarias & 5,23 & 13,06 & 149,71 \\
\hline Enfermedades del aparato genitourinario & 30,85 & 36,37 & 17,89 \\
\hline Complicaciones del embarazo, parto y puerperio & 60,11 & 68,51 & 13,97 \\
\hline Enfermedades de la piel y del tejido subcutáneo & 27,35 & 32,96 & 20,51 \\
\hline Enfermedades del sistema osteomioarticular y conectivo & 51,63 & 60,26 & 16,71 \\
\hline Anomalías congénitas & 60,37 & 73,92 & 22,44 \\
\hline Enfermedades con origen en periodo perinatal & 67,95 & 67,16 & $-1,17$ \\
\hline Síntomas, signos y estados mal definidos & 21,15 & 24,44 & 15,55 \\
\hline Lesiones y envenenamiento & 43,26 & 51,03 & 17,96 \\
\hline Neoplasias & 98,07 & 101,59 & 3,58 \\
\hline C. Endocrinas, de la nutrición, metabólicas y T. inmunidad & 47,98 & 57,08 & 18,96 \\
\hline Enfermedades de la sangre y órganos hematopoyéticos & 64,09 & 73,93 & 15,35 \\
\hline Trastornos mentales & 75,82 & 87,87 & 15,89 \\
\hline Enfermedades del SNC y órganos de los sentidos & 34,06 & 40,92 & 20,14 \\
\hline Enfermedades del sistema circulatorio & 74,47 & 80,93 & 8,67 \\
\hline Enfermedades del sistema respiratorio & 8,59 & 12,73 & 48,19 \\
\hline Enfermedades del sistema digestivo & 24,11 & 31,76 & 31,72 \\
\hline CÓDIGOSE & 42,52 & 45,69 & 7,45 \\
\hline CÓDIGOS MIL & 88,03 & 75,82 & $-13,88$ \\
\hline PROCEDIMIENTOS & 56,85 & 71,11 & 25,08 \\
\hline CÓDIGOS V & 56,07 & 18,96 & $-66,18$ \\
\hline Sin diagnóstico & 46,80 & 57,85 & 23,61 \\
\hline Total & 36,14 & 40,51 & 12,09 \\
\hline
\end{tabular}

En cuanto al número de procesos, al irse retornando al trabajo en la medida de lo posible, excepción hecha del aumento del paro y los trabajadores en ERTE, el número de procesos había caído tan solo el $1,9 \%$ interanual, cuando en el periodo del confinamiento y desescalada la caída interanual fue del 
27,04 (Tabla 4). La IT es un fenómeno anticrisis, lo que a futuro indica que una vez se retome la mejora económica contaremos con IT de más duración y mayor número de procesos, lo que se sumará a otras causas de prolongar la duración de la baja.

Tabla 4: Número de procesos a junio 20192020 y variación interanual.

\begin{tabular}{|c|c|c|}
\hline Número de procesos IT Junio 2019 & Número de procesos IT Junio $\mathbf{2 0 2 0}$ & \% Variación interanual \\
\hline 493.638 & 360.201 & 27,04 \\
\hline
\end{tabular}

En la Tabla 5 recogemos el número de procesos de IT acumulados al mes de octubre de 2019 y 2020. No siendo comparable la población trabajadora susceptible de precisar incapacidad temporal, por el aumento del desempleo, y trabajadores en ERTE, entre otras circunstancias, sí que es llamativo como repunta el número de procesos de junio a la referencia de octubre, un $25,14 \%$, acercándose a valores del año anterior, y también significativo y puede guardar relación con el aumento de las listas de espera quirúrgica como el número de procesos por «procedimientos» la caída de un 43,38\% en 2020.

Tabla 5: Comparativa de número de procesos 20192020 acumulados a octubre.

\begin{tabular}{|c|c|c|c|}
\hline Capítulo de diagnóstico & $\begin{array}{l}\text { Número de } \\
\text { procesos } 2019\end{array}$ & $\begin{array}{c}\text { Número de } \\
\text { procesos } 2020\end{array}$ & $\begin{array}{l}\% \text { diferencia } \\
\text { interanual }\end{array}$ \\
\hline Enfermedades infecciosas y parasitarias & 419.208 & 424.975 & 1,37 \\
\hline Enfermedades del aparato genitourinario & 113.748 & 104.025 & $-8,55$ \\
\hline Complicaciones del embarazo, parto y puerperio & 63.155 & 58.739 & $-7,00$ \\
\hline Enfermedades de la piel y del tejido subcutáneo & 63.549 & 53.657 & $-15,57$ \\
\hline $\begin{array}{l}\text { Enfermedades del sistema osteomioarticular y conec- } \\
\text { tivo }\end{array}$ & 1.070 .240 & 951.094 & $-11,14$ \\
\hline Anomalías congénitas & 6.680 & 5.443 & $-18,52$ \\
\hline Enfermedades con origen en periodo perinatal & 1.368 & 845 & $-38,24$ \\
\hline Síntomas, signos y estados mal definidos & 475.003 & 544.425 & 14,61 \\
\hline Lesiones y envenenamiento & 694.883 & 517.248 & $-25,57$ \\
\hline Neoplasias & 72.314 & 71.237 & $-1,49$ \\
\hline $\begin{array}{l}\text { C. Endocrinas, de la nutrición, metabólicas y T. inmu- } \\
\text { nidad }\end{array}$ & 23.728 & 23.761 & 0,13 \\
\hline Enfermedades de la sangre y órganos hematopoyéticos & 6.440 & 6.527 & 1,35 \\
\hline Trastornos mentales & 283.238 & 271.996 & $-3,97$ \\
\hline Enfermedades del SNC y órganos de los sentidos & 237.202 & 206.551 & $-12,93$ \\
\hline Enfermedades del sistema circulatorio & 85.692 & 86.379 & 0,80 \\
\hline Enfermedades del sistema respiratorio & 723.816 & 633.066 & $-12,54$ \\
\hline Enfermedades del sistema digestivo & 291.474 & 241.478 & $-17,16$ \\
\hline CÓDIGOSE & 1.746 & 2.312 & 32,41 \\
\hline CÓDIGOS MIL & 2.206 & 1.771 & $-19,72$ \\
\hline PROCEDIMIENTOS & 87.620 & 49.618 & $-43,38$ \\
\hline CÓDIGOS V & 19.372 & 393.446 & 1931 \\
\hline Sin diagnóstico & 14.332 & 18.241 & 27,27 \\
\hline Total & 4.757 .014 & 4.666 .834 & $-1,9$ \\
\hline
\end{tabular}

\subsection{COVID-19 y su influencia en las bajas prolongadas ${ }^{(14,15)}$}

Las bajas prolongadas son una pequeña parte del total de bajas que se inician, pero son las que más recursos sanitarios consumen, mayores riegos de incapacidad suponen, mayores impactos para la salud 
laboral encierran, las que suponen más problemas al retorno laboral saludable y eficaz, las que causan mayor impacto en la economía productiva de los autónomos y también las que deterioran de forma notable el sistema productivo de las empresas. La situación de crisis económica provocada por la pandemia hace que las repercusiones laborales de estas bajas prolongadas «prologadas» a su vez por el COVID-19 sean mayores, encerrando un alto riesgo de difícil retorno al trabajo, y un añadido deterioro de la salud laboral, así como un alto riesgo de pérdida del empleo o del negocio.

Para valorar esta influencia del COVID-19 en las «bajas prolongadas» o muy largas, atendemos al indicador de procesos de baja de duración superior a 365 días, a los que nos referimos bajo el acrónimo PIT (Prórroga de Incapacidad Temporal).

Por «PIT» entendemos los procesos que pasan a la valoración de Prórroga de Incapacidad Temporal, son procesos de baja que agotan duración máxima de la IT (Incapacidad Temporal) de 365 días, momento en que el INSS toma la decisión (resolución) a través de los equipos de valoración de incapacidades (EVIs) como órganos colegiados valoradores de la incapacidad, de si una situación de baja se prorroga, se le da el alta para incorporación laboral o pasa a incapacidad permanente. Cuando hablemos de PIT estaremos hablando de los procesos que pasan a la valoración de Prórroga de Incapacidad Temporal, y nos referiremos a ellos en este estudio como procesos de «baja larga» o «baja prolongada».

Método de trabajo: Analizaremos los datos por capítulos diagnósticos tanto en el momento final de este estudio, octubre 2020, como en los datos añadidos o acumulados durante el año hasta el mes de octubre, y los compararemos con los del año 2019.

Comparativa de morbilidad en PIT a mes de octubre 2020 y su referencia con el mes de octubre 2019

En el mes de octubre de 2020 (Tabla 7) el volumen de procesos de larga baja (PIT), se había incrementado en un $25,27 \%$, respecto del mes de octubre del año anterior. Las decisiones de prórroga se incrementaron en un $6,08 \%$, las de alta en un $3,41 \%$ y descendieron las declaraciones de IP en un $13,14 \%$ respecto al año 2019.

Lo que llevaría a considerar que la pandemia incrementó la duración de las bajas de forma notable y tal vez de forma inadecuada, pues más procesos alcanzaron los 365 días, y se dieron más altas para poner fin a la baja, lo que podría estar en relación con un peor control de las bajas ya que durante los meses del confinamiento total no se realizaron controles presenciales de la IT y más procesos que pasaron a prórroga en una mayor espera de que el tratamiento curara o mejorara el proceso, lo que está en relación con menor atención presencial, el aplazamiento o anulación de tratamientos, incluyendo de forma especial la rehabilitación, de pruebas diagnósticas o funcionales o de intervenciones programadas quirúrgicas no urgentes que aconteció en el confinamiento y que agravó las listas de espera, ya deterioradas.

El número de procesos que alcanzaron los 365 días en octubre de 2020 se incrementó respecto del mes de octubre del año anterior, en un 25,27\%, los procesos que pasaron a Incapacidad Permanente (IP) se incrementaron en un $8,82 \%$, los de alta en un $29,57 \%$ y las prórrogas en un 32,88\%. (Tabla 6 y Tabla 7 )

Por capítulos diagnósticos las bajas prolongadas se incrementaron de diferente forma:

- Las bajas prolongadas por enfermedades endocrinas y de la nutrición se incrementaron en un 28,50\%

- Las bajas prolongadas por trastornos mentales se incrementaron en un 28,20\%

- Las bajas prolongadas por trastornos osteomusculares se incrementaron en un $26,70 \%$.

- Las bajas prolongadas por neoplasias se incrementaron en un 26,49\%.

- Las bajas prolongadas por enfermedades respiratorias se incrementaron en un $24,27 \%$

- Las bajas prolongadas por enfermedades del sistema nervioso se incrementaron en un 22,79\%

- Las bajas prolongadas por enfermedades cardiovasculares se incrementaron en un $20,48 \%$

- Las bajas prolongadas por enfermedades digestivas se incrementaron en un 19,24\%

En cuanto al porcentaje de procesos por capítulos diagnósticos que alcanzaron los 365 días en octubre 2020 de los 28.989 totales: 
- Las bajas prolongadas por trastornos osteomusculares fueron el 47,16\%.

- Las bajas prolongadas por trastornos mentales fueron el 15,68\%

- Las bajas prolongadas por neoplasias fueron el 8,67\%.

- Las bajas prolongadas por enfermedades del sistema nervioso fueron el 7,30\%

- Las bajas prolongadas por enfermedades cardiovasculares fueron el 7.04\%

- Las bajas prolongadas por enfermedades digestivas fueron el 3,16\%

- Las bajas prolongadas por enfermedades respiratorias fueron el 1,04\%

- Las bajas prolongadas por enfermedades endocrinas y nutrición fueron el 0,91\%.

Tabla 6: Resoluciones PIT por capítulos de diagnósticos en el mes de octubre 2019

\begin{tabular}{|c|c|c|c|}
\hline \multirow{2}{*}{$\begin{array}{l}\text { Indicadores } \\
\text { Capítulo diagnóstico }\end{array}$} & \multicolumn{3}{|c|}{ Número de resoluciones $\mathbf{2 3 . 1 4 1}$} \\
\hline & $\begin{array}{l}\text { Apertura Expedien- } \\
\text { te IP }\end{array}$ & Alta & Prorroga de IT \\
\hline $\begin{array}{l}\text { Enfermedades del sistema osteomioarticular } \\
\text { y conectivo } N^{\circ} \text { de procesos } 10.790\end{array}$ & 2.701 & 3.934 & 4.155 \\
\hline$\%$ de resoluciones según decisión & 25,03 & 36,45 & 38,50 \\
\hline $\begin{array}{l}\text { Trastornos mentales } \\
\mathrm{N}^{\circ} \text { de procesos } 3.546\end{array}$ & 650 & 1.624 & 1.272 \\
\hline$\%$ de resoluciones según decisión & 18,33 & 45,79 & 35,87 \\
\hline $\begin{array}{l}\text { Neoplasias } \\
\mathrm{N}^{\circ} \text { de procesos } 2.183\end{array}$ & 892 & 399 & 892 \\
\hline$\%$ de resoluciones según decisión & 40,86 & 18,27 & 40,86 \\
\hline $\begin{array}{l}\text { Enfermedades del sistema circulatorio } \\
\mathrm{N}^{\circ} \text { de procesos } 1.694\end{array}$ & 600 & 396 & 698 \\
\hline$\%$ de resoluciones según decisión & 35,41 & 23,37 & 41,20 \\
\hline $\begin{array}{l}\text { Enfermedades del SNC y órganos de los } \\
\text { sentidos } \\
\mathrm{N}^{\circ} \text { de procesos } 1.724\end{array}$ & 526 & 543 & 655 \\
\hline$\%$ de resoluciones según decisión & 30,51 & 31,49 & 37,99 \\
\hline $\begin{array}{l}\text { Enfermedades del sistema digestivo } \\
\mathrm{N}^{\circ} \text { de procesos } 769\end{array}$ & 196 & 255 & 318 \\
\hline \% de resoluciones según decisión & 25,48 & 33,15 & 41,35 \\
\hline $\begin{array}{l}\text { Lesiones y envenenamientos } \\
\mathrm{N}^{\circ} \text { de procesos } 700\end{array}$ & 191 & 234 & 275 \\
\hline$\%$ de resoluciones según decisión & 27,28 & 33,42 & 39,28 \\
\hline $\begin{array}{l}\text { Enfermedades del aparato genitourinario } \\
\mathrm{N}^{\circ} \text { de procesos } 349\end{array}$ & 89 & 109 & 151 \\
\hline \% de resoluciones según decisión & 25,50 & 31,23 & 43,26 \\
\hline $\begin{array}{l}\text { Síntomas, signos y estados mal definidos } \\
N^{\circ} \text { de procesos } 412\end{array}$ & 92 & 180 & 140 \\
\hline \% de resoluciones según decisión & 22,33 & 43,68 & 33,98 \\
\hline $\begin{array}{l}\text { Enfermedades de la piel y del tejido subcu- } \\
\text { táneo } \\
N^{\circ} \text { de procesos } 206 \rrbracket\end{array}$ & 58 & 62 & 86 \\
\hline \% de resoluciones según decisión & 28,55 & 30,09 & 41,74 \\
\hline $\begin{array}{l}\text { Enfermedades del sistema respiratorio } \\
\mathrm{N}^{\circ} \text { de procesos } 243 \otimes\end{array}$ & 78 & 79 & 86 \\
\hline$\%$ de resoluciones según decisión & 32,09 & 32,51 & 35,39 \\
\hline
\end{tabular}




\begin{tabular}{|l|c|c|c|}
\hline Indicadores & \multicolumn{2}{|c|}{ Número de resoluciones 23.141 } \\
\hline Capítulo diagnóstico & $\begin{array}{c}\text { Apertura Expedien- } \\
\text { te IP }\end{array}$ & Alta & Prorroga de IT \\
\hline $\begin{array}{l}\text { E. Endocrinas, de la nutrición, metabólicas y } \\
\text { T. inmunidad } \\
\mathbf{N}^{\circ} \text { de procesos 207 }\end{array}$ & 68 & 69 & 70 \\
\hline \% de resoluciones según decisión & 32,85 & 33,33 & 33,81 \\
\hline $\begin{array}{l}\text { Enfermedades infecciosas y parasitarias } \\
\mathbf{N}^{\circ} \text { de procesos 107 }\end{array}$ & 28 & 36 & 43 \\
\hline \% de resoluciones según decisión & 26,16 & 33,64 & 40,18 \\
\hline Anomalías congénitas & 19 & 16 & 30 \\
\hline $\begin{array}{l}\text { Complicaciones del embarazo, parto y puer- } \\
\text { perio }\end{array}$ & 2 & 9 & 22 \\
\hline Procedimientos & 21 & 22 & 22 \\
\hline $\begin{array}{l}\text { Enfermedades de la sangre y órganos hema- } \\
\text { topoyéticos }\end{array}$ & 11 & 20 & 16 \\
\hline Códigos M & & & 1 \\
\hline Total resoluciones por decisión & $\mathbf{6 . 2 2 2}$ & $\mathbf{7 . 9 8 7}$ & $\mathbf{8 . 9 3 2}$ \\
\hline \% de resoluciones según decisión & $\mathbf{2 6 , 8 8}$ & $\mathbf{3 8 , 5 9}$ \\
\hline
\end{tabular}

Tabla 7: Resoluciones PIT por capítulos de diagnósticos mes de octubre 2020

\begin{tabular}{|c|c|c|c|}
\hline \multirow{2}{*}{$\begin{array}{l}\text { Indicadores } \\
\text { Capítulo diagnóstico }\end{array}$} & \multicolumn{3}{|c|}{ Número de resoluciones $\mathbf{2 8 . 9 8 9}$} \\
\hline & $\begin{array}{l}\text { Apertura Expedien- } \\
\text { te IP }\end{array}$ & Alta & Prorroga de IT \\
\hline $\begin{array}{l}\text { Enfermedades del sistema osteomioarticular y } \\
\text { conectivo } \\
\mathrm{N}^{\circ} \text { de procesos } 13.672\end{array}$ & 2.888 & 5.087 & 5.697 \\
\hline$\%$ de resoluciones según decisión & 21,12 & 37,20 & 41,66 \\
\hline $\begin{array}{l}\text { Trastornos mentales } \\
\mathrm{N}^{\circ} \text { de procesos } 4.546\end{array}$ & 719 & 2.280 & 1.547 \\
\hline$\%$ de resoluciones según decisión & 15,81 & 50,15 & 34,02 \\
\hline $\begin{array}{l}\text { Neoplasias } \\
\mathrm{N}^{\circ} \text { de procesos } 2.516\end{array}$ & 990 & 439 & 1.087 \\
\hline$\%$ de resoluciones según decisión & 39,34 & 17,44 & 43,20 \\
\hline $\begin{array}{l}\text { Enfermedades del sistema circulatorio } \\
\mathrm{N}^{\circ} \text { de procesos } 2.041\end{array}$ & 664 & 497 & 880 \\
\hline$\%$ de resoluciones según decisión & 32,53 & 24,35 & 43,11 \\
\hline $\begin{array}{l}\text { Enfermedades del SNC y órganos de los senti- } \\
\text { dos } \\
N^{\circ} \text { de procesos } 2.117\end{array}$ & 565 & 685 & 867 \\
\hline$\%$ de resoluciones según decisión & 26,68 & 32,35 & 40,95 \\
\hline $\begin{array}{l}\text { Enfermedades del sistema digestivo } \\
\mathrm{N}^{\circ} \text { de procesos } 917\end{array}$ & 186 & 282 & 449 \\
\hline$\%$ de resoluciones según decisión & 20,28 & 30,75 & 48,96 \\
\hline $\begin{array}{l}\text { Lesiones y envenenamientos } \\
\mathrm{N}^{\circ} \text { de procesos } 960\end{array}$ & 225 & 315 & 420 \\
\hline$\%$ de resoluciones según decisión & 23,43 & 32,81 & 43,75 \\
\hline
\end{tabular}




\begin{tabular}{|c|c|c|c|}
\hline \multirow{2}{*}{\begin{tabular}{|l|} 
Indicadores \\
Capítulo diagnóstico \\
\end{tabular}} & \multicolumn{3}{|c|}{ Número de resoluciones $\mathbf{2 8 . 9 8 9}$} \\
\hline & $\begin{array}{l}\text { Apertura Expedien- } \\
\text { te IP }\end{array}$ & Alta & Prorroga de IT \\
\hline $\begin{array}{l}\text { Enfermedades del aparato genitourinario } \\
\mathrm{N}^{\circ} \text { de procesos } 441\end{array}$ & 98 & 154 & 189 \\
\hline \% de resoluciones según decisión & 22,22 & 34,92 & 42,85 \\
\hline $\begin{array}{l}\text { Síntomas, signos y estados mal definidos } \\
\mathrm{N}^{\circ} \text { de procesos } 506 \rrbracket\end{array}$ & 118 & 203 & 185 \\
\hline \% de resoluciones según decisión & 23,32 & 40,11 & 36,56 \\
\hline $\begin{array}{l}\text { Enfermedades de la piel y del tejido subcutáneo } \\
\mathrm{N}^{\circ} \text { de procesos } 277\end{array}$ & 53 & 89 & 135 \\
\hline \% de resoluciones según decisión & 19,13 & 32,12 & 48,73 \\
\hline $\begin{array}{l}\text { Enfermedades del sistema respiratorio } \\
\mathrm{N}^{\circ} \text { de procesos } 302 \otimes\end{array}$ & 90 & 87 & 125 \\
\hline \% de resoluciones según decisión & 29,80 & 28,80 & 41,38 \\
\hline $\begin{array}{l}\text { E. Endocrinas, de la nutrición, metabólicas y T. } \\
\text { inmunidad } \\
N^{\circ} \text { de procesos } 266 \rrbracket\end{array}$ & 67 & 85 & 114 \\
\hline \% de resoluciones según decisión & 25,18 & 31,95 & 42,85 \\
\hline $\begin{array}{l}\text { Enfermedades infecciosas y parasitarias } \\
N^{\circ} \text { de procesos } 169 \rrbracket\end{array}$ & 45 & 61 & 63 \\
\hline \% de resoluciones según decisión & 26,62 & 36,09 & 37,27 \\
\hline Anomalías congénitas & 26 & 24 & 34 \\
\hline Procedimientos & 21 & 28 & 29 \\
\hline $\begin{array}{l}\text { Enfermedades de la sangre y órganos hemato- } \\
\text { poyéticos }\end{array}$ & 16 & 20 & 28 \\
\hline $\begin{array}{l}\text { Complicaciones del embarazo, parto y puer- } \\
\text { perio }\end{array}$ & & 12 & 18 \\
\hline Códigos V & & 1 & 2 \\
\hline Total resoluciones por decisión & 6.771 & 10.349 & 11.869 \\
\hline \% de resoluciones según decisión & 23,35 & 35,69 & 40,94 \\
\hline
\end{tabular}

La variación porcentual de declaraciones de IP, Alta o Prórroga, de los procesos de muy larga baja o que alcanzaron los 365 días (PIT) fue diferente por procesos según capítulos diagnósticos o para determinadas patologías.

En los trastornos osteomioarticulares se incrementó la prórroga en un $8,20 \%$ y las declaraciones de alta en un 2,05\%, en los trastornos mentales se incrementaron las altas en un 9,52\%, en las neoplasias se incrementó la prórroga en un 5,72 \%, en las enfermedades cardiovasculares se incrementaron las altas en un 4,19\%, y las prórrogas en un 4,63\%, en las enfermedades del SNC y órganos de los sentidos se incrementaron las altas en un 3,68\% y las prórrogas en un $7,79 \%$, en los procesos digestivos hubo un incremento acusado del $47,69 \%$ de las prórrogas, en las enfermedades genitourinarias destaca un incremento de las altas en un $11,81 \%$, en las enfermedades de la piel se incrementaron las altas en un $6,74 \%$ y las prórrogas en un $16,74 \%$, en las enfermedades respiratorias hubo un incremento de las prórrogas del $16,92 \%$, en las enfermedades endocrinas, metabólicas y de la nutrición se incrementaron las prórrogas en un $26,73 \%$, y en las enfermedades infecciosas el incremento se produjo en las altas del $7,28 \%$. 
La pandemia y las listas de espera o postergación para consultas externas, pruebas, operaciones y la paralización de la actividad sanitaria presencial no urgente, no COVID-19, en los meses de confinamiento más estricto, llevan a explicar esta variación por procesos.

A destacar el elevado número de altas para los trastornos genitourinarios y para los trastornos mentales, en la inmensa mayoría trastornos adaptativos, ansioso depresivos; y la prórroga de la baja para las enfermedades digestivas y para las enfermedades endocrinas metabólicas o de la nutrición. La prolongación de la baja en neoplasias.

\section{Comparativa de morbilidad en PIT acumulados en 2020 hasta octubre y los acumulados hasta el mes de octubre en 2019}

Esta comparativa (Tabla 8 y Tabla 9) nos permite tener una visión más lineal y completa de la influencia de la pandemia en las incapacidades temporales muy largas. Suma los procesos que mes a mes fueron alcanzando los 365 días. En el acumulado de procesos que alcanzaron los 365 días a octubre de 2020 y su comparativa con acumulados a octubre 2019, el número de bajas que alcanzaron los 365 días se había incrementado en un $8,25 \%$ en el acumulado. Las decisiones de prórroga se incrementaron en un $8,33 \%$, las de alta disminuyeron en $9,03 \%$ y descendieron las declaraciones de IP en un 1,91\%. La prórroga cabe cuando se espera curación o mejoría que permita trabajar en los meses de la misma. Las decisiones de prórroga tienen relación estrecha con la respuesta todavía no correcta al tratamiento, pero indudablemente con listas de espera para pruebas, tratamientos o por intervenciones que hacen que se prorrogue la baja hasta esperar respuesta evolutiva favorable y consolidación de la funcionalidad. Y por ello esta comparativa interanual de la morbilidad de los procesos de baja que alcanzaron los 365 días en baja, con cambios significativos expresa factores añadidos a la propia morbilidad de los mismos.

Por capítulos diagnósticos los 3 procesos más numerosos en PIT acumulado octubre 20, son los trastornos osteomioarticulares con el 46,35\%, los trastornos mentales, el 15,73\% y Las neoplasias, el 8,92\%.

Los trastornos osteomioarticulares, el $46,35 \%$ de los procesos PIT, en el acumulado a octubre 2020 , se incrementaron en un $17,27 \%$, se dieron un $11,34 \%$ más de prórrogas, un $11,36 \%$ menos de altas y las declaraciones de incapacidad permanente disminuyeron en un $2,40 \%$ respecto del mismo periodo de 2019.

Los trastornos mentales, el 15,73\% de los procesos PIT, en el acumulado a octubre 2020, se incrementaron en un $10,64 \%$, las prórrogas se incrementaron en un $4,97 \%$, las altas disminuyeron un $2,11 \%$ y las declaraciones de incapacidad permanente disminuyeron en un 5,29\% respecto del mismo periodo de 2019.

Las neoplasias, el 8,92\% de los procesos PIT en el acumulado a octubre 2020, las prórrogas se incrementaron en un 4,24\%, las altas disminuyeron un $31,18 \%$ y se incrementaron las declaraciones de incapacidad permanente en un $11,53 \%$, respecto del mismo periodo de 2019 . Lo que avala una mala evolución de las neoplasias en 2020.

Curiosamente las lesiones disminuyeron, en un 48,25\% pasaron de 13.595 a 7.036 en el acumulado hasta octubre.

Tabla 8: Resoluciones PIT por capítulos de diagnósticos acumulado anual a octubre 2019

\begin{tabular}{|l|c|c|c|}
\hline Indicadores & \multicolumn{2}{|c|}{ Número de resoluciones 198.526} \\
\hline Capítulo diagnóstico & $\begin{array}{c}\text { Apertura Expe- } \\
\text { diente IP }\end{array}$ & Alta & Prorroga de IT \\
\hline $\begin{array}{l}\text { Enfermedades del sistema osteomioarticular y conec- } \\
\text { tivo } \\
\mathbf{N}^{\circ} \text { de procesos 83.135 }\end{array}$ & 21.534 & 28.481 & 33.120 \\
\hline \% de resoluciones según decisión & 25,90 & 34,25 & 39,83 \\
\hline $\begin{array}{l}\text { Trastornos mentales } \\
\mathbf{N}^{\circ} \text { de procesos 30.646 }\end{array}$ & 6.029 & 12.789 & 11.828 \\
\hline
\end{tabular}




\begin{tabular}{|c|c|c|c|}
\hline \multirow{2}{*}{\begin{tabular}{|l|} 
Indicadores \\
Capítulo diagnóstico \\
\end{tabular}} & \multicolumn{3}{|c|}{ Número de resoluciones $\mathbf{1 9 8 . 5 2 6}$} \\
\hline & $\begin{array}{l}\text { Apertura Expe- } \\
\text { diente IP }\end{array}$ & Alta & Prorroga de IT \\
\hline \% de resoluciones según decisión & 19,67 & 41,73 & 38,59 \\
\hline $\begin{array}{l}\text { Neoplasias } \\
N^{\circ} \text { de procesos } 22.770\end{array}$ & 8.388 & 4.457 & 9.925 \\
\hline \% de resoluciones según decisión & 36,83 & 19,57 & 43,58 \\
\hline $\begin{array}{l}\text { Lesiones y envenenamientos } \\
\mathrm{N}^{\circ} \text { de procesos } 13.595\end{array}$ & 3.352 & 3.880 & 6.063 \\
\hline \% de resoluciones según decisión & 24,65 & 28,53 & 44,95 \\
\hline $\begin{array}{l}\text { Enfermedades del sistema circulatorio } \\
\mathrm{N}^{\circ} \text { de procesos } 14.066\end{array}$ & 4.929 & 3.363 & 5.774 \\
\hline \% de resoluciones según decisión & 35,04 & 23,90 & 41,04 \\
\hline $\begin{array}{l}\text { Enfermedades del SNC y órganos de los sentidos } \\
\mathrm{N}^{\circ} \text { de procesos } 14.009\end{array}$ & 4.177 & 4.101 & 5.731 \\
\hline \% de resoluciones según decisión & 29,81 & 29,27 & 40,90 \\
\hline $\begin{array}{l}\text { Enfermedades del sistema digestivo } \\
\mathrm{N}^{\circ} \text { de procesos } 5.915\end{array}$ & 1.564 & 1.778 & 2.573 \\
\hline \% de resoluciones según decisión & 26,44 & 30,05 & 43,49 \\
\hline $\begin{array}{l}\text { Síntomas, signos y estados mal definidos } \\
\mathrm{N}^{\circ} \text { de procesos } 3.542\end{array}$ & 847 & 1.325 & 1.370 \\
\hline \% de resoluciones según decisión & 23,91 & 37,40 & 38,67 \\
\hline $\begin{array}{l}\text { Enfermedades del aparato genitourinario } \\
\mathrm{N}^{\circ} \text { de procesos } 2.566\end{array}$ & 644 & 826 & 1.096 \\
\hline \% de resoluciones según decisión & 25,09 & 32,19 & 42,71 \\
\hline $\begin{array}{l}\text { Enfermedades del sistema respiratorio } \\
N^{\circ} \text { de procesos } 2.525\end{array}$ & 882 & 679 & 964 \\
\hline \% de resoluciones según decisión & 34,93 & 26,89 & 38,17 \\
\hline $\begin{array}{l}\text { Enfermedades de la piel y del tejido subcutáneo } \\
\mathrm{N}^{\circ} \text { de procesos } 1.573\end{array}$ & 413 & 487 & 673 \\
\hline \% de resoluciones según decisión & 26,25 & 30,95 & 42,78 \\
\hline $\begin{array}{l}\text { E. Endocrinas, de la nutrición, metabólicas y T. inmu- } \\
\text { nidad } \\
N^{\circ} \text { de procesos } 1.427\end{array}$ & 424 & 448 & 555 \\
\hline \% de resoluciones según decisión & 29,71 & 31,39 & 38,89 \\
\hline $\begin{array}{l}\text { Procedimientos } \\
\mathrm{N}^{\circ} \text { de procesos } 962\end{array}$ & 252 & 272 & 438 \\
\hline \% de resoluciones según decisión & 26,19 & 28,27 & 45,53 \\
\hline $\begin{array}{l}\text { Enfermedades infecciosas y parasitarias } \\
\mathrm{N}^{\circ} \text { de procesos } 969\end{array}$ & 257 & 319 & 393 \\
\hline \% de resoluciones según decisión & 26,52 & 32,90 & 40,55 \\
\hline $\begin{array}{l}\text { Anomalías congénitas } \\
N^{\circ} \text { de procesos } 554\end{array}$ & 186 & 148 & 220 \\
\hline \% de resoluciones según decisión & 33,57 & 26,71 & 39,71 \\
\hline $\begin{array}{l}\text { Enfermedades de la sangre y órganos hematopoyéticos } \\
N^{\circ} \text { de procesos } 387\end{array}$ & 104 & 110 & 173 \\
\hline$\%$ de resoluciones según decisión & 26,87 & 28,42 & 44,70 \\
\hline Complicaciones del embarazo, parto y puerperio & 21 & 52 & 104 \\
\hline Códigos M & 1 & 4 & 3 \\
\hline Enfermedades con origen en periodo perinatal & & & \\
\hline
\end{tabular}




\begin{tabular}{|l|c|c|c|}
\hline Indicadores & \multicolumn{2}{|c|}{ Número de resoluciones 198.526} \\
\hline Capítulo diagnóstico & $\begin{array}{c}\text { Apertura Expe- } \\
\text { diente IP }\end{array}$ & Alta & Prorroga de IT \\
\hline Códigos E & & & \\
\hline Códigos V & & & \\
\hline Total & 54.004 & 63.519 & 81.003 \\
\hline \% de resoluciones según decisión & 27,20 & 31,99 & 40,80 \\
\hline
\end{tabular}

Tabla 9: Resoluciones PIT por capítulos de diagnósticos acumulado anual a octubre 2020

\begin{tabular}{|c|c|c|c|}
\hline \multirow{2}{*}{\begin{tabular}{|l} 
Indicadores \\
Capítulo diagnóstico
\end{tabular}} & \multicolumn{3}{|c|}{ Número de resoluciones $\mathbf{2 1 5 . 4 4 2}$} \\
\hline & $\begin{array}{l}\text { Apertura } \\
\text { Expedien- } \\
\text { te IP }\end{array}$ & Alta & Prorroga de IT \\
\hline $\begin{array}{l}\text { Enfermedades del sistema osteomioarticular y conectivo } \\
\mathrm{N}^{\circ} \text { de procesos } 99.873\end{array}$ & 25.255 & 30.324 & 44.294 \\
\hline \% de resoluciones según decisión & 25,28 & 30,36 & 44,35 \\
\hline $\begin{array}{l}\text { Trastornos mentales } \\
\mathrm{N}^{\circ} \text { de procesos } 33.909\end{array}$ & 6.318 & 13.853 & 13.738 \\
\hline \% de resoluciones según decisión & 18,63 & 40,85 & 40,51 \\
\hline $\begin{array}{l}\text { Neoplasias } \\
N^{\circ} \text { de procesos } 19.237\end{array}$ & 7.904 & 2.592 & 8.741 \\
\hline \% de resoluciones según decisión & 41,08 & 13,47 & 45,43 \\
\hline $\begin{array}{l}\text { Enfermedades del sistema circulatorio } \\
\mathrm{N}^{\circ} \text { de procesos } 15.974\end{array}$ & 5.410 & 3.216 & 7.348 \\
\hline \% de resoluciones según decisión & 33,86 & 20,13 & 45,99 \\
\hline $\begin{array}{l}\text { Enfermedades del SNC y órganos de los sentidos } \\
\mathrm{N}^{\circ} \text { de procesos } 12.008\end{array}$ & 4.594 & 4.222 & 6.992 \\
\hline \% de resoluciones según decisión & 38,25 & 35,15 & 58,22 \\
\hline $\begin{array}{l}\text { Lesiones y envenenamientos } \\
\mathrm{N}^{\circ} \text { de procesos } 7.036\end{array}$ & 1.798 & 1.922 & 3.316 \\
\hline \% de resoluciones según decisión & 25,55 & 27,31 & 47,12 \\
\hline $\begin{array}{l}\text { Enfermedades del sistema digestivo } \\
\mathrm{N}^{\circ} \text { de procesos } 6.866\end{array}$ & 1.776 & 1.818 & 3.272 \\
\hline$\%$ de resoluciones según decisión & 25,86 & 26,47 & 47,65 \\
\hline $\begin{array}{l}\text { Síntomas, signos y estados mal definidos } \\
\mathrm{N}^{\circ} \text { de procesos } 3.736\end{array}$ & 839 & 1.246 & 1.651 \\
\hline \% de resoluciones según decisión & 22,41 & 33,35 & 44.19 \\
\hline $\begin{array}{l}\text { Enfermedades del aparato genitourinario } \\
\mathrm{N}^{\circ} \text { de procesos } 3.376\end{array}$ & 931 & 987 & 1.458 \\
\hline \% de resoluciones según decisión & 27,57 & 29,23 & 43,18 \\
\hline $\begin{array}{l}\text { Enfermedades del sistema respiratorio } \\
N^{\circ} \text { de procesos } 2.591\end{array}$ & 810 & 667 & 1.114 \\
\hline$\%$ de resoluciones según decisión & 31,26 & 25,74 & 42,99 \\
\hline Enfermedades de la piel y del tejido subcutáneo & 506 & 519 & 945 \\
\hline \% de resoluciones según decisión 1.970 & 25,68 & 26,34 & 47,96 \\
\hline $\begin{array}{l}\text { E. Endocrinas, de la nutrición, metabólicas y } \mathrm{T} \text {. inmunidad } \\
\mathrm{N}^{\circ} \text { de procesos } 1.953\end{array}$ & 576 & 500 & 877 \\
\hline
\end{tabular}




\begin{tabular}{|c|c|c|c|}
\hline \multirow{2}{*}{$\begin{array}{l}\text { Indicadores } \\
\text { Capítulo diagnóstico }\end{array}$} & \multicolumn{3}{|c|}{ Número de resoluciones $\mathbf{2 1 5 . 4 4 2}$} \\
\hline & $\begin{array}{l}\text { Apertura } \\
\text { Expedien- } \\
\text { te IP }\end{array}$ & Alta & Prorroga de IT \\
\hline$\%$ de resoluciones según decisión & 29,49 & 25,60 & 44,90 \\
\hline $\begin{array}{l}\text { Enfermedades infecciosas y parasitarias } \\
\mathrm{N}^{\circ} \text { de procesos } 1.216\end{array}$ & 298 & 329 & 589 \\
\hline$\%$ de resoluciones según decisión & 24,50 & 27,05 & 48,43 \\
\hline $\begin{array}{l}\text { Anomalías congénitas } \\
\mathrm{N}^{\circ} \text { de procesos } 590\end{array}$ & 157 & 154 & 279 \\
\hline \% de resoluciones según decisión & 26,61 & 26,10 & 47,28 \\
\hline $\begin{array}{l}\text { Procedimientos } \\
\mathrm{N}^{\circ} \text { de procesos } 586\end{array}$ & 158 & 176 & 252 \\
\hline$\%$ de resoluciones según decisión & 26,96 & 30,03 & 43,03 \\
\hline $\begin{array}{l}\text { Enfermedades de la sangre y órganos hematopoyéticos } \\
N^{\circ} \text { de procesos } 497\end{array}$ & 130 & 124 & 243 \\
\hline$\%$ de resoluciones según decisión & 26,15 & 24,94 & 48,89 \\
\hline Complicaciones del embarazo, parto y puerperio & 26 & 63 & 123 \\
\hline Códigos V & & 1 & 4 \\
\hline Códigos M & 1 & & 3 \\
\hline Enfermedades con origen en periodo perinatal & 1 & 1 & 1 \\
\hline Total & 57.488 & 62.714 & 95.240 \\
\hline$\%$ de resoluciones según decisión & 26,68 & 29,10 & 44,20 \\
\hline
\end{tabular}

\subsection{La incapacidad temporal por COVID-19}

La IT COVID-19 por aislamiento, infección y TES (Trabajadores Especialmente Sensibles) suponía al final de octubre 2020 el 38,73\% de todas las bajas (4.666.834). 1.807.695 bajas por COVID-19 de 4.666 .834 bajas totales acumuladas a octubre. Según datos suministrados por el Ministerio de Sanidad a 14 de octubre de 2020 se habían infectado entre 20 a 65 años (edad laboral) 925.036 personas, puestas en relación con número de ITs por infección a esa fecha 485.740, supondría que el 52,51 \% de los infectados entre 20 y 65 años a nivel Nacional causó IT por Infección. A esa fecha 14 de octubre, se habían dado 1.807 .695 bajas, $1.281 .793(70,90 \%)$ por aislamiento, 485.740 por infección $(26,87 \%)$, y 40.162 por TES (2,22\%), habiendo finalizado 1.640 .611 , es decir $92,82 \%$.

\subsubsection{IT COVID desde el inicio de la pandemia a 14 octubre 2020 (Cuadro 2)}

Cuadro 2: Datos de infectados Ministerio Sanidad. Datos IT INSS

\begin{tabular}{|c|r|r|r|r|r|r|r|r|}
\hline Total IT & $\begin{array}{c}\text { IT \%oo } \\
\text { trabajadores }\end{array}$ & $\begin{array}{c}\text { IT } \\
\text { infección }\end{array}$ & $\begin{array}{c}\text { Duración } \\
\text { media }\end{array}$ & $\begin{array}{c}\text { Total } \\
\text { Infectados } \\
\text { 20 a } 65 \text { a. }\end{array}$ & $\begin{array}{c}\text { IT } \\
\text { aislamiento }\end{array}$ & $\begin{array}{c}\text { Duración } \\
\text { media }\end{array}$ & $\begin{array}{c}\text { IT } \\
\text { TES }\end{array}$ & $\begin{array}{c}\text { Duración } \\
\text { media }\end{array}$ \\
\hline 1.807 .695 & 955,22 & 485.740 & 22,83 & 925.036 & 1.281 .793 & 15,50 & 40.162 & 42,94 \\
\hline
\end{tabular}

En cuanto a las bajas de Trabajadores Especialmente Sensibles (TES) a 14 de octubre, se habían producido 40.162 IT, y finalizadas a 14 octubre 36.924, el 91,94\%. La duración media de la IT de los TES 42,94 días.

Con posterioridad a estos datos se pudo acceder a datos acumulados a final de octubre 2020, recogidos en la página web de la seguridad social en diciembre. Se habían alcanzado 1.909.770 procesos, con una duración media acumulada de la IT global por COVID-19 (tanto por infección, aislamiento y TES) 
finalizado octubre era de 17,24 días, con una incidencia del 13,65 \%o trabajadores protegidos, con una prevalencia (procesos abiertos al final del periodo) de 10,46 cada \%o trabajadores (Tabla 10).

Tabla 10: IT COVID-19 acumulado a OCTUBRE 2020 duración media incidencia y prevalencia.

\begin{tabular}{|c|c|c|c|c|c|c|}
\hline Autonomía & $\begin{array}{l}\text { Duración } \\
\text { media }\end{array}$ & $\begin{array}{c}\text { Inciden- } \\
\text { cia media } \\
\text { mensual } \\
\text { por cada \%o } \\
\text { trabajadores } \\
\text { protegidos }\end{array}$ & $\begin{array}{c}\text { Número } \\
\text { de proce- } \\
\text { sos inicia- } \\
\text { dos en el } \\
\text { periodo }\end{array}$ & $\begin{array}{l}\text { Prevalencia } \\
\text { por cada \%o } \\
\text { trabajadores }\end{array}$ & $\begin{array}{l}\text { Número de } \\
\text { procesos en } \\
\text { vigor al final } \\
\text { del periodo }\end{array}$ & $\begin{array}{c}\text { Trabajadores } \\
\text { protegidos }\end{array}$ \\
\hline ANDALUCIA & 15,89 & 9,44 & 190.157 & 10,56 & 26.805 & 2.538 .410 \\
\hline ARAGÓN & 15,29 & 18,14 & 80.584 & 14,83 & 8.277 & 558.087 \\
\hline ASTURIAS & 16,72 & 9,07 & 24.883 & 10,36 & 3.606 & 347.968 \\
\hline BALEARES & 13,92 & 11,60 & 43.392 & 4,18 & 1.818 & 434.523 \\
\hline CANARIAS & 15,50 & 7,37 & 44.921 & 2,99 & 2.305 & 770.326 \\
\hline CANTABRIA & 16,65 & 11,87 & 19.825 & 8,14 & 1.719 & 211.201 \\
\hline $\begin{array}{l}\text { CASTILLAY } \\
\text { LEÓN }\end{array}$ & 17,38 & 13,53 & 89.167 & 14,48 & 12.063 & 832.917 \\
\hline $\begin{array}{l}\text { CASTILLA-LA } \\
\text { MANCHA }\end{array}$ & 17,81 & 16,55 & 89.751 & 10,28 & 7.070 & 687.482 \\
\hline CATALUÑA & 17,36 & 16,59 & 436.019 & 14,34 & 47.476 & 3.310 .230 \\
\hline EXTREMADURA & 16,14 & 8,99 & 21.866 & 12,33 & 3.796 & 307.776 \\
\hline GALICIA & 18,69 & 7,11 & 52.278 & 7,75 & 7.212 & 930.328 \\
\hline MADRID & 19,71 & 16,50 & 389.007 & 6,55 & 19.404 & 2.963 .161 \\
\hline MURCIA & 14,16 & 16,15 & 73.429 & 14,61 & 8.465 & 579.517 \\
\hline NAVARRA & 13,99 & 22,74 & 48.857 & 16,78 & 4.596 & 273.848 \\
\hline LA RIOJA & 16,16 & 17,92 & 17.954 & 11,53 & 1.460 & 126.616 \\
\hline $\begin{array}{l}\text { COM. VALEN- } \\
\text { CIANA }\end{array}$ & 18,26 & 10,09 & 145.728 & 8,51 & 15.864 & 1.863 .664 \\
\hline PAIS VASCO & 15,32 & 19,54 & 136.829 & 12,82 & 11.350 & 885.269 \\
\hline CEUTA & 16,88 & 14,88 & 2.439 & 41,54 & 820 & 19.740 \\
\hline MELILLA & 12,87 & 17,35 & 2.684 & 30,99 & 611 & 19.718 \\
\hline Total Nacional & 17,24 & 13,65 & 1.909 .770 & 10,46 & 184.717 & 17.660 .781 \\
\hline
\end{tabular}

La distribución por comunidades autónomas fue singularmente diferente tanto en la incidencia, como duración y prevalencia. En cuanto a la duración destacan Madrid con 19,71 días, Galicia 18,69 y Comunidad Valenciana con 18,16; en cuanto a incidencia Navarra con 22,74, País Vasco con 19,54 y Aragón con 18,14: en prevalencia destacan Ceuta con 41,54, Melilla con 30,99 muy significativamente, y Navarra con 16, 78. (Fig. 1, Fig. 2, Fig. 3). 


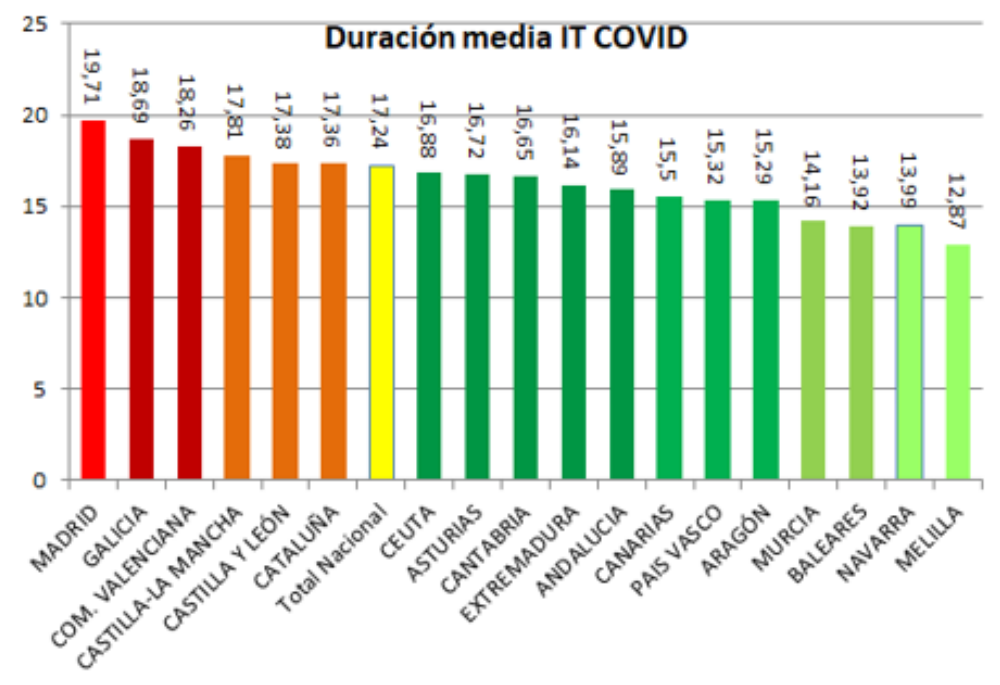

Figura 1: Duración media IT COVID-19.

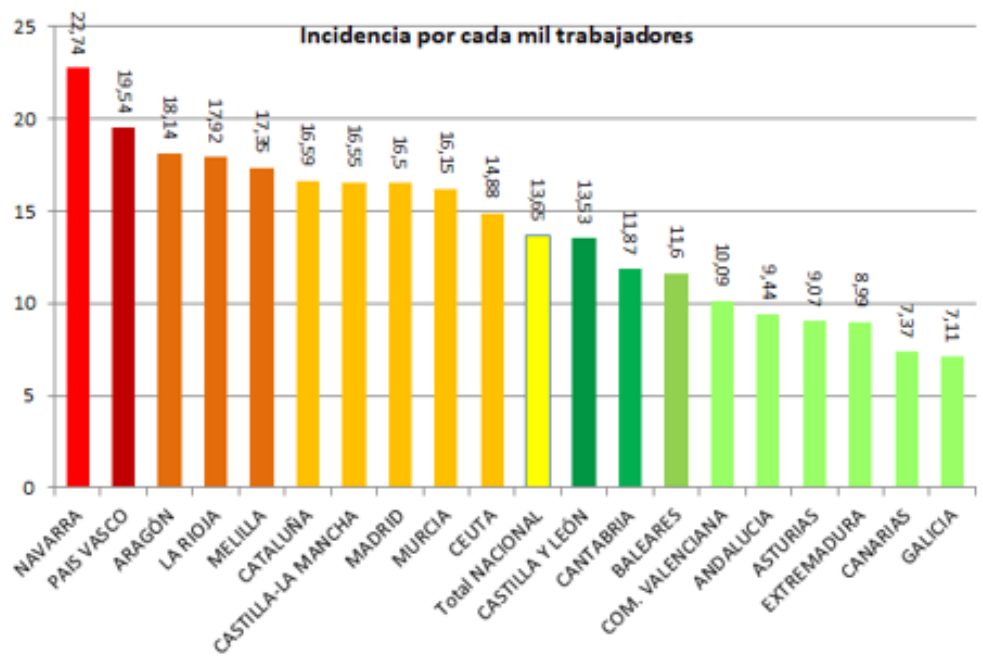

Figura 2: Incidencia IT COVID-19 por cada mil trabajadores. 


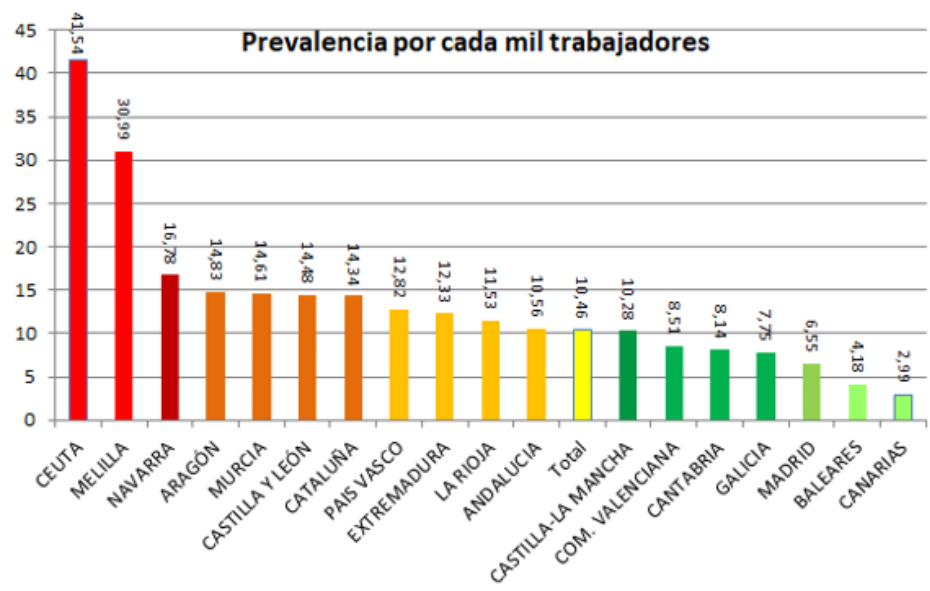

Figura 3: Prevalencia IT COVID-19 por cada mil trabajadores.

\subsection{La gestión de la incapacidad temporal en la primera ola}

Aludimos a gestión de la incapacidad, como las medidas y acciones para resolver la misma.

La otra gestión de la IT, la gestión «administrativa» o gestión de las prestaciones por parte de la Seguridad Social fue excelente pues de forma urgente se articularon cambios normativos, instrucciones interdepartamentales, guías y recomendaciones para determinar procederes que permitían proteger mediante esta prestación las situaciones de incapacidad temporal con inmediatez, dotándola así mismo de una mayor cuantía y una más completa protección abarcando las situaciones de infección, contacto o trabajo de riesgo COVID-19. Así mismo se dieron las instrucciones oportunas para la correcta gestión de las prestaciones económicas derivadas de la otra IT No COVID-19. También se ordenó el aplazamiento de notificaciones de resoluciones o la ampliación de plazos en determinados procedimientos.

Nos centraremos en la gestión de la incapacidad, como las medidas y acciones sanitarias y de evaluación y control médico para resolver la misma.

Había que establecer medidas drásticas para atender la pandemia y evitar los contagios y el colapso sanitario.

La atención sanitaria se paralizó para procesos No COVID-19 no urgentes, para paliar la no atención médica presencial se obligaba al contacto telefónico con enormes dificultades para ello por sobresaturación. Sobre un sistema público sanitario que, aunque con diferencias autonómicas padecía un incremento de las listas de espera para consultas, pruebas y cirugías, y una sobresaturación de algunos servicios en cuanto a dotación de personal y demanda asistencial, el colapso sanitario por COVID-19, precipitó un colapso sanitario de la atención No COVID-19.

En el confinamiento se cerró la actividad presencial de las inspecciones médicas del INSS, de las inspecciones médicas las comunidades autónomas y de los controles presenciales de IT en mutuas.

Se normó de forma urgente la protección mediante la IT COVID-19 y diversas instrucciones para no paralizar la gestión de la prestación económica de la incapacidad temporal.

Se arbitró un procedimiento para la extensión telefónica de los partes de baja, y este control telefónico, no presencial se utilizaría para la extensión de los partes de confirmación o de «prórroga» de la incapacidad temporal. También se implementó la atención sanitaria telefónica.

Los servicios de prevención colaboraron de forma ejemplar con la atención primaria en la información y valoración de espacios laborales de riesgo. Toda una novedad pues hasta ese momento lo cierto era 
que eran ámbitos de gestión en compartimentos estancos y sin comunicación en lo que a la incapacidad se refiere.

Pero la correcta gestión sanitaria y médico evaluadora de la incapacidad exige el reconocimiento médico presencial para objetivar las limitaciones funcionales de una enfermedad respecto del trabajo.

Por todo ello el deterioro en la gestión era inevitable por dos razones, la primera la adecuada gestión de las bajas exige poder disponer de tratamiento adecuado y atención presencial de los procesos que las causan para conseguir la pronta recuperación funcional, la segunda la incapacidad temporal es una prestación con alto riesgo moral, y este riesgo se incrementa exponencialmente sin control presencial de las bajas.

En cuanto a las listas de espera, los aplazamientos o anulaciones de consultas, pruebas diagnósticas, pruebas funcionales, tratamientos no urgentes, incluyendo el rehabilitador, e intervenciones programadas no urgentes, hicieron que la gestión de la incapacidad resultara inadecuada. Si un proceso no es atendido adecuadamente es obvio que la recuperación se retrasará incluso como es de esperar que su evolución clínica será mucho peor. Sobre ello nos extenderemos en el apartado 4 de este artículo en lo referente a la atención prestada en la pandemia y su traslación a la incapacidad laboral. Añadiríamos a lo anterior las dificultades de atención presencial y de contacto asistencial de procesos No COVID-19. La curación de un proceso conlleva tratamiento en tiempo y forma adecuado, lo que significa acceso al mismo a tiempo, por lo que el retraso o aplazamiento del tratamiento o las propias dificultades en el contacto asistencial causan de forma directa una peor respuesta y evolución de cualquier enfermedad y más en las enfermedades graves.

En cuanto a la potenciación de la atención telefónica, tanto en atención primaria como especializada fue un hecho, era inevitable y razonable, pero también es imprescindible explicar con claridad sus motivos, sus objetivos y valorar su eficiencia en la atención a los pacientes. La atención sanitaria telefónica tiene sus riesgos uno organizacional decidir que es urgente y que puede no y de ser así resuelto por contacto telefónico a posteriori, otro las dificultades que el contacto telefónico implican (Javier Carnicero Giménez de Azcarate. Artículo la «Atención Primaria en los tiempos del COVID-19». Diario de Navarra 18/8/2020)(16).

En cuanto al riesgo moral(17,18,19) lo entendemos como la posibilidad de que un acontecimiento se suceda en virtud del comportamiento humano. El riesgo moral en la incapacidad laboral es el riesgo que corremos al valorar una situación de incapacidad sobre la confianza en la buena fe del interesado, o en el obrar de buena fe del ciudadano que va a referirnos su verdadera situación de incapacidad sin distorsión, sin tergiversación o sin engaño. El riesgo moral se define en los sistemas de aseguramiento como el riesgo en la correcta adecuación de la prestación asegurada de incapacidad influenciado por la propia conducta del presunto incapacitado y la asimetría en el conocimiento y la información auténtica y exacta sobre como de verdad se siente y se muestra el incapacitado y cómo de verdad lo está. Pues el presunto incapacitado tiene la información auténtica de cómo se siente y qué y cómo debe trasmitir cómo se siente y como está respondiendo al tratamiento y en definitiva cómo evoluciona y qué secuelas mantiene. Es decir, la actitud expresada ante el controlador o gestor de la IT y sus controles, es lo que engendra el riesgo moral. Con control de la incapacidad temporal telefónico o a través de datos recogidos en la historia, a menudo con numerosas alusiones a control del proceso telefónico, es obvio que el riesgo de que las bajas se prolongaran era muy grande.

También es cierto, que en la época de la «normalización» de junio a octubre 2020, y hasta el inicio de la segunda ola se multiplicaron por diez las demandas por parte del trabajador del alta voluntaria para poder trabajar en los procesos de IT en control del INSS, comparando con mismo periodo del año anterior. En una mezcla de manifiesta recuperación funcional, necesidad económica imperiosa de incorporación al mercado laboral y situación de precariedad en el empleo que obliga a evitar riesgos de perder el trabajo. 


\section{Las otras enfermedades en la pandemia de COVID-19 y las implicaciones en la incapacidad laboral}

El 14 de marzo de 2020, el Gobierno de España decretó el estado de alarma que supuso la instauración de medidas extraordinarias para controlar la transmisión comunitaria viral, restringiendo la libre movilidad, siendo los trabajadores esenciales los únicos autorizados a salir de sus hogares. Estas restricciones se mantendrían hasta la desescalada y la vuelta a una nueva realidad, retornando de forma paulatina a la vida social y laboral, sin restricciones, al cabo de casi cien días.

La pandemia provocó un colapso sanitario sin precedentes, crisis sanitaria que hizo preciso priorizar la atención del COVID-19 y paralizó la atención no urgente no grave de los procesos no COVID-19 Se cancelaron Intervenciones quirúrgicas, pruebas diagnósticas, tratamientos no urgentes, y la atención primaria y especializada perdió accesibilidad, se perdió eficacia y capacidad de resolución sobre las otras patologías no COVID-19; tratando de resolver la atención sanitaria no presencial implementando la atención telefónica, lo que era razonable y procedente, pero indudablemente tiene riesgo de ser deficiente, y sobre todo ser percibida por los ciudadanos como inadecuada y en ocasiones como desatención sanitaria. Además, el cribaje de las llamadas del ciudadano y la propia prestación de contacto telefónico médico evidenció un sistema sanitario que no estaba preparado para ello, valga recordar que para la prestación sanitaria es imprescindible la atención presencial, el contacto médico paciente, ya suficientemente dañado y falto de componente humanista en un sistema público saturado. o En paralelo a la crisis sanitaria por la pandemia sucedió la crisis sanitaria y no menos importante derivada de la falta de atención correcta en tiempo y forma que causaría un agravamiento o mala evolución de algunas enfermedades y que tal vez en un futuro podremos valorar como pérdida de años de vida, disminución de la esperanza de vida y elevación de las cifras de mortalidad que esta crisis sanitaria ocasionó. Sin olvidarnos del sobre coste sanitario y económico que ello provocará.

Durante el confinamiento y consolidado el fenómeno en los meses siguientes se percibía en una parte de los ciudadanos una sensación de miedo a contagiarse a salir de casa y más a acudir a los hospitales lo que ha podido afectar a la detección temprana y a empeorar el pronóstico.

La emisión de bajas y su control en estos tiempos del Covid-19 fue percibida por atención primaria como actividad no clínica, no estrictamente médica, y que no hacía sino sobrecargar los centros de salud, de forma no estrictamente presencial necesaria, así se extendieron los partes de baja por Covid-19 de forma telefónica, y luego para el resto de procesos, al menos en los tiempos más estrictos del confinamiento; modalidad que parece haber venido para quedarse, en otros procesos como los de corta duración.

La norma exige la extensión del parte de baja, salvo excepciones de grave urgencia, se realice tras el reconocimiento médico oportuno del paciente, se entiende para objetivar las limitaciones sobrevenidas a consecuencia de una enfermedad o lesión y su significación incapacitante laboral, es decir, en cuanto y de qué manera limitan para el trabajo que el trabajador desempeña. Añádase a ello que el control evolutivo resulta riesgoso en su veracidad si se descansa en la buena fe de la respuesta a una consulta telefónica.

Ya hemos citado que la baja, la incapacidad temporal es una prestación con alto «riesgo moral»(18,19), entendido este riesgo como el derivado de la emisión de una parte de baja y su prórroga en la confianza de que el trabajador relata dolencias y limitaciones ciertas, así como perdurar su situación en el relato de la evolución y respuesta al tratamiento. El riesgo moral en la incapacidad laboral es el riesgo que corremos al valorar una situación de incapacidad laboral sobre la confianza en la buena fe del interesado, o en el obrar de buena fe del ciudadano que va a referirnos su verdadera situación de incapacidad sin distorsión, sin tergiversación o sin engaño. 


\subsection{Situaciones sanitarias a destacar}

\subsubsection{Listas de espera ${ }^{(20,21)}$}

En el periodo del confinamiento, se priorizó la atención al COVID-19, ello llevó a la anulación de las consultas presenciales NO COVID-19, no urgentes, por ello las listas de espera se incrementaron para consultas, pruebas diagnósticas, pruebas funcionales, rehabilitación y para intervenciones programadas. El ministerio de sanidad recogía en su informe «Sistema de información sobre listas de espera en el Sistema Nacional de Salud SISLE-SNS, situación a 30 de junio de 2020» que la lista de espera quirúrgica había aumentado en 50 días hasta los 170 de media, y la de consultas había crecido a los 115 días por la pandemia, empeorando una situación que ya era deficiente con anterioridad. Más de un tercio de los pacientes en lista de espera $(33,8 \%)$ deberá esperar más de seis meses para recibir la atención quirúrgica requerida y las intervenciones quirúrgicas se habían reducido hasta junio un 36\%. El 52,7\% de los pacientes deberá esperar más de sesenta días para ser atendidos en el caso de las consultas.

Por especialidades médicas, la traumatología es la que más tiempo de espera acumula 146 días, en dermatología 117 días de espera, 104 en neurología, 103 para digestivo, 81 días para cardiología, o 75 días para cirugía general y del aparato digestivo, El mantenimiento de la incapacidad laboral tiene una conexión directa con recibir atención temprana y correcta, indudablemente el aumento de las listas de espera tenía que llevar a prolongar la baja a prorrogar su situación, y a una peor respuesta al tratamiento empeorando su pronóstico.

Los procesos osteomusculares sufrieron el aplazamiento de la rehabilitación ${ }^{(22)}$, y esta debe llegar de forma temprana si se quiere sea útil, esto explicaría su mala evolución y la prolongación de la incapacidad temporal, que en los casos de bajas que alcanzaron los 365 días se incrementó en un $26 \%$.

En 2014 el Instituto Nacional de la Seguridad Social reconocía que el 12\% de las bajas se prolongaba por estar el trabajador en una lista de espera médica, en la actualidad el $25 \%$ de los procesos en que se prorroga la incapacidad temporal más allá de los 365 días en octubre 2020 se debía a espera de tratamiento o porque durante los meses del confinamiento no pudo ser atendido o porque se postergó el mismo.

Las listas de espera explican el incremento de la duración media de la IT en un 84,48\%. durante el periodo del "confinamiento» y la «desescalada» y cómo esta duración media permanecía incrementada en un 12,09\% en la comparación de las bajas acumuladas a octubre 2020 con la del año anterior; así como el incremento del $60,73 \%$ de la duración de las enfermedades endocrinas, el 50,09\% de las enfermedades del sistema nervioso, el $45 ; 42 \%$ de las enfermedades de la sangre, el $45,09 \%$ de las enfermedades digestivas, el 39,03\% de las enfermedades de la piel, el 35,63\% de la duración media de los trastornos osteomioarticulares, el 34,12\% de la duración media de las neoplasias, el 34,09\% de las enfermedades genitourinarias, el 33,37\% de las enfermedades cardiovasculares, el $31,94 \%$ de los «procedimientos», y el $29,56 \%$ de los trastornos mentales.

El Incremento desproporcionado de la duración media en las enfermedades respiratorias del 503,58\%, o en las enfermedades infecciosas $215,88 \%$, los códigos V $149,19 \%$, está en relación estrecha con los procesos COVID-19. Recordar como las bajas prolongadas (PIT) se incrementaron por enfermedades endocrinas y de la nutrición en un $28,50 \%$, por trastornos mentales en un $28,20 \%$, por trastornos osteomusculares en un $26,70 \%$, por neoplasias en un $26,49 \%$, por enfermedades respiratorias en un $24,27 \%$, por enfermedades del sistema nervioso en un $22,79 \%$, por enfermedades cardiovasculares en un $20,48 \%$ y por enfermedades digestivas en un $19,24 \%$.

\subsubsection{Salud mental}

Se da como tiempo de espera medio en salud mental para procesos adaptativos o reactivos en torno a los 90 días. La pandemia ha tenido una repercusión sobre la salud mental, así como poner de manifiesto el deterioro del sistema sanitario y su ineficacia ${ }^{(23)}$. La sobrecarga asistencial y la mayor demanda asistencial por procesos adaptativos o ansioso depresivos, exige una atención personalizada y temprana, más humanizada con contacto directo y menos medicalizada, y de no hacerlo empeora la recuperación funcional. 
COVID-19 duplica el riesgo de desarrollar una enfermedad psiquiátrica posterior ${ }^{(24)}$ en comparación con otros procesos. El impacto de la pandemia sobre la salud mental ha sido documentado con evidencia, con una prevalencia aumentada en torno al 16\% para la depresión y la ansiedad por la situación obligada de confinamientos, los problemas económicos, el distanciamiento físico y social, el temor al contagio, y la preocupación ante la incertidumbre de la salud ${ }^{(25)}$.

El propio confinamiento y la «pandemia de la soledad»(26,27) puede estar en la causa de muchos procesos ansioso depresivos o adaptativos. La pandemia ha visualizado la crisis de la atención psiquiátrica y urge la necesidad de cambio(28).

El consumo de medicamentos para ansiedad, depresión y problemas de sueño subió un 4\% durante la primera ola, según datos de IQVIA y Federación Empresarial de Farmacéuticos Españoles.

Añadir que los trastornos mentales son la segunda causa de bajas prolongadas y que además acompañan como comorbilidad a otros procesos como los debidos a dolor crónico. Lo puede explicar el incremento de la duración media de las bajas por enfermedad mental en un el 29,56, y el incremento en procesos de larga baja, los que superaban los 365 días, en un $28,20 \%$.

Los trastornos mentales tuvieron un incremento del $13,46 \%$ en el periodo de confinamiento y desescalada (marzo a junio 2020). Su duración media en este periodo se incrementó un $29,56 \%$. Este incremento en la duración de las bajas se mantuvo en el periodo acumulado hasta octubre, que recogería la vuelta a la normalidad, con un incremento de su duración media en un $15,89 \%$. Los trastornos mentales supusieron la segunda causa de las bajas prolongadas (que alcanzan 365 días) el 15,73\% del total de procesos PIT, tras los trastornos osteomioarticulares el $46,35 \%$ de los PIT y se incrementaron en un en un $28,20 \%$ respecto del año anterior. Se incrementaron las prórrogas de la baja en un $10,64 \%$. Lo que supone un impacto severo en la salud mental y su repercusión en la incapacidad temporal laboral.

\subsubsection{Cáncer en la pandemia ${ }^{(29,30,31)}$}

Resulta llamativo que el número de neoplasias diagnosticadas disminuyera en 2020 en un 21\% según estudio de la Asociación Española Contra el Cáncer lo que obviamente no quiere decir no se produjeran. La demora en el diagnóstico del cáncer y en el tratamiento empeora de forma significativa la supervivencia y las posibilidades de sanación.

En el confinamiento se paralizaron los programas de screening y de diagnóstico precoz y las revisiones, también se retrasaron determinadas pruebas y sus resultados. Hubo menos diagnósticos nuevos, por tanto, y se triplicaron los seguimientos telefónicos de los procesos ya diagnosticados, con la dificultad de contacto que ello supone y la pérdida de la eficiencia sanitaria. Algunos tratamientos se aplazaron caso de algunas cirugías no urgentes o caso de los cánceres de sangre los trasplantes de médula ósea.

Por otra parte, la coronafobia, pudo hacer que algunos pacientes aplazaran las consultas o temieran acudir a los hospitales.

Todo esto explica que respecto a la incapacidad temporal por neoplasias, se incrementara la duración de estas bajas en el confinamiento y desescalada en un $34,12 \%$, y en ese periodo la incidencia de las bajas por cáncer disminuyó en un $8,14 \%$ respecto del año anterior; en cuanto a las bajas prolongadas de más de 365 por cáncer, en el acumulado a octubre, se incrementaran en un 26,49\% y que se prorrogaran un 4,24\% más que en el mismo periodo 2019, que las altas por curación o mejoría funcional disminuyeron un $31,18 \%$ y se incrementaron las declaraciones de incapacidad permanente en un $11,53 \%$, en el 2020 respecto al acumulado a octubre2019, lo que avala una mala evolución de las neoplasias en 2020 como consecuencia transversal del COVID-19.

\subsubsection{Infarto ${ }^{(32)}$}

En el confinamiento, según datos de la Sociedad Española de Cardiología (SEC), los diagnósticos de infarto disminuyeron en un $40 \%$ su diagnóstico, tal vez imputable al miedo a acudir a los hospitales. Pero también aumentó el tiempo entre la isquemia y la atención sanitaria lo que supone un elevado riesgo de mala evolución, fruto de las dificultades atencionales y por la coronafobia. En cuanto a las 
angioplastias en estudio recogido por la SEC de 71 hospitales de las 17 comunidades la cifra de angioplastias primarias pasó de 429 a 258.

\subsection{5. $\operatorname{Ictus}^{(33)}$}

En los procesos vasculocerebrales tipo ictus, siendo una patología grave pudo apreciarse con dramatismo y evidencia como durante el confinamiento hubo una disminución significativa en el número de ingresos, y un aumento de la mortalidad. Así se referencia en artículo tras valoración del impacto del brote de COVID-19 en los ingresos por ictus isquémico y la mortalidad hospitalaria en el noroeste de España.

La Sociedad Española de Neurología (SEN) registró en torno a un 33\% menos de ingresos en el confinamiento y un mayor retraso en requerir atención hospitalaria.

\subsubsection{Los procesos cardiovasculares}

Las bajas por enfermedades cardiovasculares se incrementaron en un $7,38 \%$ en el periodo del confinamiento y desescalada y se incrementó su duración media en un 33,37\%, esta mayor duración se mantuvo incrementada en el $8,67 \%$ en el periodo de vuelta a la normalidad, periodo acumulado de bajas a octubre 2020. Las bajas prolongadas (PIT) por enfermedades cardiovasculares se incrementaron en un $20,48 \%$, con un incremento de las prórrogas de la incapacidad temporal en un $4,63 \%$. Todo ello conlleva un empeoramiento de la salud cardiovascular constatado y peor evolución manteniendo su incapacidad laboral.

\section{Conclusiones}

La incapacidad temporal por COVID-19 se reguló normativamente de forma expresa, recogiendo la incapacidad temporal por «sospecha aislamiento», la incapacidad temporal por infección contagio y la incapacidad temporal para trabajadores sensibles. Supuso la integración de la protección preventiva laboral amparada en una la prestación económica dotada de mayor cuantía. Analizando las consecuencias de la pandemia en la primera ola y antes del inicio de la segunda, meses de marzo a octubre, el impacto del COVID-19 supuso un elevado incremento de la duración media de las bajas laborales por todos los procesos, en el confinamiento y la desescalada en un $84,48 \%$ y un incremento de las bajas prolongadas de más de 365 días en un $25,27 \%$. En consecuencia, el COVID-19 como efecto colateral supuso una mala evolución del resto de procesos, prolongando la duración de las incapacidades temporales, lo que supone un empeoramiento de la salud laboral, un mayor riesgo de no retorno al trabajo, un mayor gasto en prestaciones y un deterioro económico para empresas y autónomos. La IT específica por COVID-19 suponía al final de octubre 2020 el 38,73\% de todas las bajas.

El efecto del incremento de las listas de espera para consultas, pruebas o intervenciones quirúrgicas no urgentes, así como la anulación o postergación de consultas o tratamientos supuso una duración mayor de las bajas laborales y el empeoramiento de la salud laboral, en consecuencia, al no poder disponer de tratamiento en tiempo y forma.

En el confinamiento y la desescalada la duración media de las bajas se incrementó en un 84,48\%; por procesos el incremento fue del $503,58 \%$ en las enfermedades respiratorias, del $215,88 \%$, en las enfermedades infecciosas, $60,73 \%$ en las enfermedades endocrinas, $45 ; 42 \%$ de las enfermedades de la sangre, $45,09 \%$ de las enfermedades digestivas, 35,63\% en los trastornos osteomioarticulares, 34,12\% en las neoplasias, $33,37 \%$ en las enfermedades circulatorias, $31,94 \%$ de los «procedimientos», y un incremento del $29,56 \%$ de los trastornos mentales.

Las bajas prolongadas (PIT) de 365 días se incrementaron en un 25,27\%, respecto del mes de octubre del año anterior. Las bajas prolongadas por enfermedades endocrinas y de la nutrición se incrementaron en un 28,50 , por trastornos mentales en un 28,20 , por trastornos osteomusculares en un 26,70 , por neoplasias en un $26,49 \%$, por enfermedades respiratorias en un $24,27 \%$, por enfermedades del sistema nervioso en un $22,79 \%$, por enfermedades cardiovasculares en un $20,48 \%$, y por enfermedades digestivas en un $19,24 \%$. 
Como consecuencia del COVID-19, se expuso a un riesgo añadido y nuevo a la población trabajadora, sanitarios y socio sanitarios sufrieron la enfermedad como consecuencia directa de su trabajo por enfermedad de indudable carácter profesional.

Los efectos del COVID-19 en el retraso de pruebas, cirugías o tratamientos en procesos «No COVID-19» y las dificultades de contacto asistencial empeoraron la salud laboral, prolongando las situaciones de incapacidad y elevando el riesgo que encierran las incapacidades prolongadas de no retorno laboral por la esperada mala evolución de cualquier proceso cuando no puede ser tratado y atendido de forma temprana.

\section{Bibliografía}

1. Real Decreto Ley 6 de 2020, de 10 de marzo. BOE, $n^{\circ}$ 62, (11-03-2020). Disponible en: https://www. boe.es/eli/es/rdl/2020/03/10/6

2. Criterio 4/2020 de la Seguridad Social DGOSS. Dirección General de Ordenación de la Seguridad Social, (12-03-2020). Disponible en: https://prevencion.fremap.es/Doc\%20VARIOS/Noticias/4-CRITERIO\%20VIRUS\%20SARS-Co-4

3. Disposición adicional vigésimo primera del Real Decreto-ley $11 / 2020$, de 31 de marzo. BOE, $n^{\circ} 91$, (01-04-2020). Disponible en: https://www.boe.es/eli/es/rdl/2020/03/31/11

4. Procedimiento de actuación para los servicios de prevención de riesgos laborales frente a la exposición al SARS-CoV-2. Ministerio de Sanidad, (08-04-2020). Disponible en: http://iisgetafe.es/wp-content/ uploads/2020/04/PrevencionRRLL_COVID-19

5. Actualización a 15 de abril de 2020 de las instrucciones aclaratorias relativas al nuevo procedimiento de remisión de partes de los servicios públicos de salud (SPS) por coronavirus. Instituto Nacional de la Seguridad Social, (15-04-2020). Disponible en: https:/fedesp.es/wp-content/uploads/2020/03/ACTUALIZACI\%C3\%93N-15-04-ACLARACIONES-RDL-6-2020-REMISI\%C3\%93N-DE-PARTES-SPS.pdf

6. Real Decreto-ley 19/2020, de 26 de mayo, por el que se adoptan medidas complementarias en materia agraria, científica, económica, de empleo y Seguridad Social y tributarias para paliar los efectos del COVID-19. BOE, nº 150, (27-05-2020). Disponible en: https://www.boe.es/eli/es/rdl/2020/05/26/19/con

7. Actualización a 17 de junio de 2020 de las instrucciones aclaratorias relativas a los procesos de Incapacidad Temporal emitidos a los Trabajadores Especialmente Sensibles por especial vulnerabilidad frente al Coronavirus SARS- CoV-2. Sociedad Española de Médicos Generales y de familia [sede Web]. Madrid: SEMG Madrid [citado 18 jun 2020]. Covid 19. Disponible en: https://bit.ly/3AssgkX

8. Procedimiento de actuación para los servicios de prevención de riesgos laborales frente a la exposición al SARS-CoV-2. Ministerio de Sanidad, (08-06-2020). Disponible en: https://bit.ly/3nTq7LQ

9. Procedimiento de actuación para los servicios de prevención de riesgos laborales frente a la exposición al SARS-CoV-2. Ministerio de Sanidad, (16-07-2021). Disponible en: https://bit.ly/3hSyxPB

10. Vicente-Pardo JM, López-Guillén-García A. Incapacidad Temporal por Coronavirus (COVID-19), enfermedad profesional en personal sanitario [monografía en Internet]. Córdoba: Prevencionar.com; 2020 [citado 28 abr 2020]. Disponible en: https://bit.ly/3hSp1Ma

11. Vicente-Pardo JM, López-Guillén-García A. Coronavirus COVID-19 e Incapacidad Temporal; Contingencia, Confinamiento y Prevención [monografía en Internet]. Córdoba: Prevencionar.com; 2020 [citado 20 ago 2020]. Disponible en: https://bit.ly/2W0Jy9S

12. Vicente-Pardo JM, López-Guillén-García A. «Coronavirus» COVID-19 Enfermedad Profesional en Personal Sanitario, un derecho incuestionable a reparar [monografía en Internet]. Córdoba: Prevencionar.com; 2020 [citado 18 may 2020]. Disponible en: https://bit.ly/3hUUiOC

13. World Health Organization. Coronavirus disease (COVID-19) outbreak: rights, roles and responsibilities of health workers, including key considerations for occupational safety and health. Who. 2020 
[citado 19 mar 2020]. WHO reference number: WHO/2019-nCov/HCW_advice/2020_2. Disponible en: https://bit.ly/3EGc1Da

14. Vicente-Pardo JM. Reflexión sobre los problemas a la reincorporación laboral tras incapacidades médicas largas. Med Segur Trab (Madr). 2016;62(242):49-65. Disponible en: http://scielo.isciii.es/scielo. php?script=sci_arttext\&pid=S0465-546X2016000100006\&lng=es\&tlng=es.

15. Vicente-Pardo JM, López-Guillén-García A. ¿Combatir o Prevenir el absentismo por incapacidad temporal laboral? [monografía en Internet]. Córdoba: Prevencionar.com; 2020 [citado 14 dic 2020]. Disponible en: https://bit.ly/3nTz8EG

16. Carnicero-Giménez de Azcarate J. Atención Primaria en tiempos del COVID-19. Diario de Navarra. 18 ago 2020;Opinión. Disponible en: https://bit.ly/3CrHV4o

17. López-Guillén-García A, Vicente-Pardo JM. Necesidad de políticas de retorno al trabajo tras incapacidad laboral prolongada, en materia de seguridad social. Med Segur Trab (Madr). 2018;64(253);379-401. Disponible en: http://scielo.isciii.es/scielo.php?script=sci_arttext\&pid=S0465-546X2018000400379\&lng=es\&tlng=es.

18. Vicente-Pardo JM. Incapacidad laboral, riesgo moral y riesgo laboral [monografía en Internet]. Córdoba: Prevencionar.com; 2018 [citado 8 may 2018]. Disponible en: http://prevencionar. com/2018/05/08/incapacidad-laboral-riesgo-moral-y-riesgo-laboral/

19. Campolieti, M. Moral Hazard and Disability Insurance: On the Incidence of Hard-to-Diagnose Medical Conditions in the Canada/Quebec Pension Plan Disability Program. Can Public Policy. 2002;28(3):41941. DOI: $10.2307 / 3552230$. Disponible en: https://doi.org/10.2307/3552230

20. Sistema de información sobre listas de espera en el Sistema Nacional de Salud SISLE-SNS, situación a 30 de junio de 2020. Ministerio de Sanidad, (2020). Disponible en: https://bit.ly/39oO9Wo

21. Oliver N, Barber X, Roomp K, Roomp K. Assessing the Impact of the COVID-19 Pandemic in Spain: Large-Scale, Online, Self-Reported Population Survey. J Med Internet Res. 2020;22(9):e21319. DOI: 10.2196/21319. Disponible en: https://pubmed.ncbi.nlm.nih.gov/32870159/

22. Avellanet M, Boada-Pladellorens $A$, Pages-Bolibar E. Rehabilitación en época de confinamiento. Rehabilitacion (Madr). 2020;54(4):269-75. DOI: 10.1016/j.rh.2020.05.003. Disponible en: https://doi.org/10.1016/j.rh.2020.05.003.

23. Buitrago-Ramírez F, Ciurana-Misol R, Fernández-Alonso MC, Luis-Tizón J. Pandemia de la COVID-19 y salud mental: reflexiones iniciales desde la atención primaria de salud española. Aten Primaria. 2021;53(1):89-101. DOI: 10.1016/j.aprim.2020.06.006. Disponible en: https://doi.org/10.1016/j. aprim.2020.06.006

24. Taquet M, Luciano S, Geddes JR, Harrison PJ. Bidirectional associations between COVID-19 and psychiatric disorder: retrospective cohort studies of 62354 COVID-19 cases in the USA. Lancet Psychiatry. 2021;8(2):130-40. DOI: 10.1016/S2215-0366(20)30462-4. Disponible en: https://doi.org/10.1016/S22150366(20)30462-4

25. Cénat JM, Blais-Rochette C, Kokou-Kpolou CK, Noorishad PG, Mukunzi JN, McIntee SE, et al. Prevalence of symptoms of depression, anxiety, insomnia, posttraumatic stress disorder, and psychological distress among populations affected by the COVID-19 pandemic: A systematic review and meta-analysis. Psychiatry Res. 2021;295. DOI: 10.1016/j.psychres.2020.113599. Disponible en: https://doi. org/10.1016/j.psychres.2020.113599

26. Fancourt D, Steptoe A, Bu F. Trajectories of anxiety and depressive symptoms during enforced isolation due to COVID-19 in England: a longitudinal observational study. Lancet Psychiatry. 2021;8(2):141-9. DOI: 10.1016/S2215-0366(20)30482-X. Disponible en: https://doi.org/10.1016/S2215-0366(20)30482-X

27. Palgi Y, Shrira A, Ring L, Bodner E, Avidor S, Bergman Y, et al. The loneliness pandemic: Loneliness and other concomitants of depression, anxiety and their comorbidity during the COVID-19 outbreak. J Affect Disord. 2020;275:109-11. DOI: 10.1016/j.jad.2020.06.036. Disponible en: https://doi.org/10.1016/j.jad.2020.06.036 
28. Moreno C, Wykes T, Galderisi S, Nordentoft M, Crossley N, Jones N, et al. How mental health care should change as a consequence of the COVID-19 pandemic. Lancet Psychiatry. 2020;7(9):813-24. DOI: 10.1016/S2215-0366(20)30307-2. Disponible en: https://doi.org/10.1016/S2215-0366(20)30307-2

29. Sociedad Española de Anatomía Patológica, Sociedad Española de Enfermería Oncológica, Sociedad Española de Hematología y Hemoterapia, Sociedad Española de Oncología Médica, Sociedad Española de Oncología Radioterápica, Asociación Española Contra el Cáncer. COVID-19 y cáncer: Resultados del estudio elaborado por AECC, SEAP, SEEO, SEHH, SEOM y SEOR. Madrid; 21 de diciembre de 2020. Disponible en: https://bit.ly/3nXz32M

30. Hanna TP, King WD, Thibodeau S, Jalink M, Paulin GA, Harvey-Jones E, et al. Mortality due to cancer treatment delay: systematic review and meta-analysis. BMJ. 2020;371:m4087. DOI: 10.1136/bmj. m4087. Disponible en: https://doi.org/10.1136/bmj.m4087

31. Lopez C. Oncología, desde la trinchera. Revista Española de Economía de la Salud [revista en Internet]. 2020 [citado 23 abr 2020]. Disponible en: https://economiadelasalud.com/?s=Oncolog\%C3\%ADa\%2C+desde+la+trinchera

32. Rodríguez-Leor O, Cid-Alvarez B, Perez-Prado A, Rossello X, Ojeda S, Serrador A, et al. Impact of COVID-19 on ST-segment elevation myocardial infarction care: The Spanish experience. Rev Esp Cardiol (english edition). 2020;73(12):994-1002. DOI: 10.1016/j.rec.2020.08.002. Disponible en: https://doi. org/10.1016/j.rec.2020.08.002

33. Tejada-Meza H, Lambea-Gil A, Sancho-Saldaña A, Martínez-Zabaleta M, Riva-Juez P, López-Cancio-Martínez E, et al. Impact of COVID-19 outbreak on ischemic stroke admissions and in-hospital mortality in North-West Spain. Int J Stroke. 2020;15(7):755-62. DOI: 10.1177/1747493020938301. Disponible en: https://pubmed.ncbi.nlm.nih.gov/32525468/ 